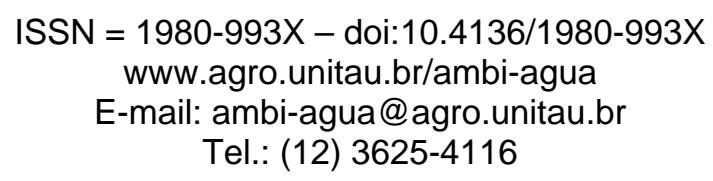

\title{
Tratamento aeróbio conjugado de lodos de tanques sépticos e resíduos sólidos orgânicos domiciliares \\ (doi:10.4136/ambi-agua.107)
}

\author{
Monica Maria Pereira da Silva ${ }^{1}$; José Tavares de Sousa²; Beatriz Susana Ovruski \\ Ceballos $^{1}$; Wanderson Barbosa da Silva Feitosa ${ }^{3}$; Valderi Duarte Leite ${ }^{2}$ \\ ${ }^{1}$ Departamento de Biologia, Centro de Ciências Biológicas e da Saúde - Universidade Estadual da Paraíba \\ E-mail:monicaea@terra.com.br; biaceballos@hotmail.com \\ ${ }^{2}$ Departamento de Química, Centro de Ciências e Tecnologia - UEPB \\ E-mail: jtdes@uol.com.br; valderi123@globo.com \\ ${ }^{3}$ Universidade Federal de Campina Grande \\ E-mail: wanderson123@oi.com.br
}

\section{RESUMO}

Objetivou-se avaliar a co-compostagem como alternativa tecnológica ao tratamento de lodos de tanques sépticos com resíduos sólidos orgânicos domiciliares oriundos de municípios de pequeno e médio portes. Os lodos e os resíduos sólidos orgânicos domiciliares foram coletados em Cabaceiras, Caraúbas e Queimadas, estado da Paraíba. O experimento consistiu de quatro tratamentos com três repetições, totalizando 12 reatores, de configuração cilíndrica em polietileno de $100 \mathrm{~L}$ de capacidade. Cada reator foi alimentado com $50 \mathrm{~kg}$ de substrato com composição variável em função da fração de lodo: $0 \%, 10 \%$, 20\% e 30\%. O reviramento manual foi realizado três vezes por semana e a temperatura foi monitorada diariamente. A total destruição de ovos de helmintos em período diferenciado em função da fração de lodo (14, 28, 35 e 63 dias) e a transformação média de 54,1\% de lodos em biossólidos classe A e classe B, com características favoráveis ao uso em culturas agrícolas em 91 dias, expressaram a viabilidade do tratamento por co-compostagem de lodos de tanques sépticos multicâmaras de uso coletivo para os municípios de pequeno e médio portes.

Palavras-chave: Tanque séptico; lodos; co-compostagem; biossólidos.

\section{Treatment aerobic conjugate of sludges of septic tanks and household organic solid wastes}

\section{ABSTRACT}

It was aimed at to evaluate the co-composting as technological alternative to the treatment of sludges of septic tanks with household organic solid wastes originating from cities of small and medium loads. The sludges and the domiciliary organic solid waste were collected in Cabaceiras, Caraúbas and Queimadas, state of Paraíba. The experiment consisted of four treatments with three repetitions, totaling 12 reactors, of cylindrical configuration in polyethylene of $100 \mathrm{~L}$ of capacity. Each reactor was fed with $50 \mathrm{~kg}$ substratum with variable composition in function of the sludge fraction: $0 \%, 10 \%, 20 \%$ and $30 \%$. The manual turning was accomplished three times a week and the temperature was monitored daily. The total destruction of helminth eggs in period differentiated in function of the sludges fraction (14, 28, 35 and 63 days) and the medium transformation of $54.1 \%$ of sludges in biosolids class $\mathrm{A}$ and class B, with favorable characteristics to the use in agricultural cultures in 91 days, expressed the viability of the treatment for co-composting of sludges of tanks septic multichamber of collective use for the cities of small and medium load.

Keywords: Septic tank; sludges; co-composting; biossolids. 


\section{INTRODUÇÃO}

A utilização de tanques sépticos é muito frequente no Brasil e em países da África, Ásia e da América Latina (Leite et al., 2006; Koottape et al., 2001), em consequência dos baixos índices de cobertura de rede coletora de esgotos e das vantagens desse tipo de tecnologia: simplicidade, baixo custo, poucos requisitos para operação e manutenção (Pradhan et al., 2008), baixa produção de sólidos e baixo consumo de energia (Aquino e Chernicharo, 2005), possibilidade de reaproveitamento do efluente (Summerfelt e Penne, 2007) e de retorno dos nutrientes ao solo (Montangero e Belevi, 2007), efluente fácil de ser submetido ao tratamento secundário (Andrade Neto e Campos, 1999) e vida útil longa (USEPA, 1999a).

Na Paraíba, em municípios de pequeno e médio porte situados no semiárido, geralmente os tanques sépticos multicâmaras de uso coletivo constituem a única forma de tratamento de esgotos, sendo, algumas vezes, seguidos de filtro anaeróbio. Segundo estimativa de Silva (2008) para os municípios situados no semiárido paraibano, a produção anual de lodos nesses tipos de sistemas varia de 15 a $22 \mathrm{kgST} / \mathrm{hab}$. ano.

Em virtude das características indesejáveis que detém o lodo de esgoto, tais como: instabilidade biológica e péssima qualidade higiênica (Van Haandel e Além Sobrinho, 2006), o seu lançamento no meio ambiente sem tratamento representa risco de contaminação e poluição. À medida que ocorre a estabilização e higienização, essas características podem ser atenuadas. O gerenciamento de lodos de esgotos, porém, é de grande complexidade e de alto custo (Andreoli et al., 2001). As alternativas tecnológicas buscam possibilitar a atenuação dessa complexidade e subsidiar o seu reaproveitamento, no intuito de proteger a saúde pública e o meio ambiente.

A co-compostagem dos lodos de esgotos com resíduos sólidos orgânicos vem sendo apontada na literatura internacional (Banegas et al., 2007; Tognetti et al., 2007; Koné et al., 2007) e nacional (Correa et al., 2007; Silva et al., 2008) como alternativa de tratamento dos lodos de esgotos por propiciar a sua estabilização e higienização (Gea et al., 2007), originando um produto favorável à aplicação como fertilizante orgânico em diferentes tipos de solos e que pode atender às restrições ambientais e legais (Kranert et al., 2008).

De acordo com Silva (2008), a média da produção per capita de resíduos sólidos orgânicos domiciliares em municípios do semiárido paraibano varia de 106 a 131 kg/hab.ano. O que aponta para a potencialidade quantitativa de uso desses resíduos em co-compostagem com lodos de tanques sépticos multicâmaras de uso coletivo.

A co-compostagem constitui uma tecnologia de baixo custo, de fácil operação e manutenção (Correa et al., 2007) que permite viabilizar o processo de bioestabilizaçcão de lodo de esgoto sanitário e a superação das limitações inerentes à compostagem de lodo isolado: baixa relação $\mathrm{C} / \mathrm{N}$, alto teor de umidade, baixa diversidade de organismos e granulometria fina (Pinto, 2001). Essas limitações dificultam a ação dos organismos na estabilização, consequentemente, o aumento dos níveis de temperatura e a destruição e/ou inativação de ovos de helmintos são prejudicados. Estes últimos são considerados os mais resistentes, entre os micro-organismos patogênicos por Koné et al. (2007) e Metcalf \& Eddy (2003).

O principal objetivo deste trabalho consistiu em avaliar a co-compostagem como alternativa tecnológica ao tratamento de lodos de tanques sépticos com resíduos sólidos orgânicos domiciliares oriundos de municípios de pequeno e médio portes, requerendo a caracterização química, física e sanitária desses resíduos. 


\section{MATERIAL E MÉTODOS}

\subsection{Caracterização da pesquisa}

O trabalho foi realizado de agosto de 2005 a junho de 2008 nos municípios de Cabaceiras, Caraúbas e Queimadas, no estado da Paraíba. A escolha desses municípios teve por critérios: residências na área urbana com esgotos encaminhados a tanque séptico de uso coletivo, número de habitantes, localização na região semiárida e aceitabilidade da administração pública.

A pesquisa experimental foi realizada na EXTRABES - Estação Experimental de Tratamentos Biológicos de Esgotos Sanitários e no laboratório do PROSAB - Programa de Saneamento Básico, da Universidade Federal de Campina Grande e da Universidade Estadual da Paraíba, localizados no bairro do Tambor, em Campina Grande-PB (latitude: $7^{\circ} 13^{\prime}$ 50”; longitude: $35^{\circ} 52$ ' 52”, a $551 \mathrm{~m}$ acima do nível do mar).

\subsection{Caracterização de lodos de tanques sépticos coletivos e resíduos sólidos orgânicos domiciliares}

Os lodos foram coletados em diferentes câmaras de tanques sépticos coletivos localizados nos municípios de Cabaceiras, Caraúbas e Queimadas, utilizando-se de uma bomba de sucção.

Nas câmaras coletaram-se dez amostras de pontos distintos, formando-se uma amostra composta de $10 \mathrm{~kg}$ de lodos. O procedimento foi realizado três vezes. Totalizando-se 24 amostras no tanque séptico de Cabaceiras, nove em Caraúbas e três em Queimadas. O número de amostra diferenciada decorreu das características construtivas dos tanques sépticos estudados (Tabela 1).

Tabela 1. Características dos tanques sépticos coletivos estudados em Cabaceiras, Caraúbas e Queimadas, no estado da Paraíba. Agosto a novembro de 2006.

\begin{tabular}{l|c|c|c}
\hline \multirow{2}{*}{\multicolumn{1}{c|}{ Características }} & \multicolumn{3}{c}{ Tanque séptico coletivo } \\
\cline { 2 - 4 } \multicolumn{1}{c}{ Ano de Construção } & Cabaceiras & Caraúbas & Queimadas \\
\hline Número de câmaras & $\mathbf{1 9 9 8}$ & $\mathbf{2 0 0 0}$ & $\mathbf{1 9 9 8}$ \\
Comprimento (m) & 8 & 3 & 2 \\
Largura (m) & 14 & 9,2 & 6,0 \\
Profundidade (m) & 11 & 4,30 & 3,0 \\
Número de ligações & 2,8 & 2,3 & 2,3 \\
Número de contribuintes & 80 & 60 & 60 \\
Tempo de detenção hidráulica (dia) & 400 & 180 & 180 \\
Vazão (m ${ }^{3} /$ dia) & 8 & 2 & - \\
Volume útil (m ${ }^{3}$ ) & 40 & 18 & 18 \\
\hline & 313 & 38 & 0 \\
\hline
\end{tabular}

Para a caracterização física, química e sanitária, os resíduos sólidos orgânicos domiciliares foram coletados na fonte geradora (110 residências) em três semanas consecutivas e dias alternados: segunda-feira, quarta-feira e sexta-feira. Constituindo-se três amostras compostas por município.

As famílias foram previamente cadastradas, tendo por norteamento: localização (ruas ou avenidas distintas), esgoto ligado ao tanque séptico coletivo e interesse prévio em participar do projeto. Este antecedeu tanto, a coleta dos resíduos sólidos, como a de lodos de tanques sépticos coletivos. Em Queimadas, além do cadastramento de 30 famílias que encaminhavam esgotos ao tanque séptico coletivo, cadastraram-se 50 famílias, visando à aquisição de resíduos sólidos orgânicos domiciliares em quantidade adequada à instalação do experimento de co-compostagem. 
SILVA, M. M. P.; SOUZA, J. T.; CEBALlOS, B. S. O.; FEITOSA, W. B. S.; LEITE, V. D. Tratamento aeróbio conjugado de lodos de tanques sépticos e resíduos sólidos orgânicos domiciliares. Ambi-Agua, Taubaté, v. 4, n. 3, p. 123-143, 2009. (doi:10.4136/ambi-agua.107)

As análises físicas e químicas de lodos de tanques sépticos e resíduos sólidos orgânicos domiciliares seguiram as recomendações do Standard Methods for Examination of the Water and Wastewater (APHA et al., 1998), exceto para carbono orgânico total - COT (Quadro 1).

Para identificação e quantificação de ovos de helmintos, utilizou-se o método de Meyer et al. (1978) modificado. As modificações referem-se à preparação da amostra: 1)peso da amostra (25 g); 2) lavagens prévias com solução de água sanitária a 50\%; 3) filtração dupla por filtro de nylon. O procedimento de filtração dupla foi adotado apenas para os resíduos sólidos orgânicos, em virtude da granulometria e visando aumentar eficiência de recuperação de ovos de helmintos.

Para a análise da viabilidade de ovos de helmintos usou-se a técnica de coloração rápida, utilizando-se solução de safranina a $0,1 \%$. A técnica baseia-se no uso de corante biológico para detectar as trocas de permeabilidade da membrana vitelina dos ovos.

Quadro 1. Métodos utilizados para caracterização física, química e sanitária dos lodos dos tanques sépticos coletivos nos municípios de Cabaceiras, Caraúbas e Queimadas Paraíba. Agosto a novembro de 2006.

\begin{tabular}{|c|c|}
\hline Parâmetros & Métodos Utilizados \\
\hline Umidade (\%) & Gravimétrico \\
pH (unidade) & Potenciométrico \\
Gravimétrico \\
Sólidos totais voláteis-STV (\%ST) & Kiehl (1998) $(1,8 x S T V)$ \\
Carbono Orgânico Total -COT (\%ST) & Método semimicro Kjeldhal com digestão. \\
Nitrogênio total - NTK (\%ST) & persulfato de amônio \\
Fósforo total -P(\%ST) & Fotometria de chama \\
& Meyer (1978) modificado \\
Potássio-K(\%ST) & \\
\hline
\end{tabular}

\subsection{O sistema experimental de co-compostagem de lodos de tanques sépticos coletivos e resíduos sólidos orgânicos domiciliares}

O sistema experimental consistiu de quatro tratamentos (T) com três repetições (R), totalizando 12 reatores aeróbios de polietileno de cor preta, de configuração cilíndrica com capacidade volumétrica unitária de $100 \mathrm{~L}$, diâmetro de $1,56 \mathrm{~m}$, altura 0,70 m e disposição casualizada. Cada reator foi alimentado com $50 \mathrm{~kg}$ de substrato (lodos de tanque séptico e resíduos sólidos orgânicos domiciliares) e recebeu composição variável em função da fração de lodo: 0\% (T1), 10\% (T2), 20\% (T3) e 30\% (T4 4) (Figura 1).

Para montagem do experimento foram coletados $200 \mathrm{~kg}$ de lodos dos tanques sépticos de Cabaceiras e Caraúbas e uma tonelada de resíduos sólidos orgânicos nas residências de Queimadas. A opção por Queimadas decorreu da quantidade de resíduos orgânicos necessária para montagem do experimento, da facilidade de acesso e de transporte.

Os lodos foram submetidos ao pré-tratamento por meio de secagem natural em uma caixa cilíndrica de amianto, durante 30 dias, objetivando-se alcançar o teor de umidade próximo a 70\%. Os resíduos orgânicos domiciliares também passaram pelo pré-tratamento, trituração, para obtenção da granulometria ideal à co-compostagem.

O sistema experimental foi monitorado diariamente durante 91 dias, sempre no mesmo horário, às 14 horas, por meio de aferição de temperatura, utilizando-se de termômetro de haste de mercúrio e por observação direta. A escolha do horário decorreu da montagem do sistema experimental. A aferição de temperatura ocorreu em três pontos da massa de substrato: superfície, centro e base, para a qual foram perfurados seis furos no centro (altura: $35 \mathrm{~cm}$ ) e seis próximos à base (altura: $5 \mathrm{~cm}$ ) de cada reator. 
SILVA, M. M. P.; SOUZA, J. T.; CEBALLOS, B. S. O.; FEITOSA, W. B. S.; LEITE, V. D. Tratamento aeróbio conjugado de lodos de tanques sépticos e resíduos sólidos orgânicos domiciliares. Ambi-Agua, Taubaté, v. 4, n. 3, p. 123-143, 2009. (doi:10.4136/ambi-agua.107)

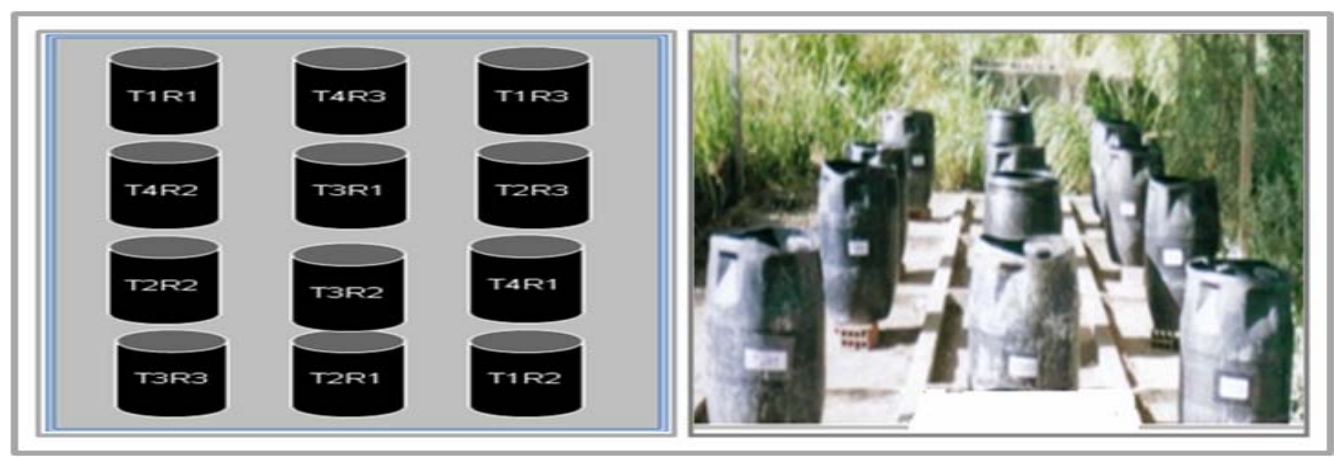

Figura 1. Disposição casualizada dos reatores para os diferentes tratamentos de cocompostagem de lodos de tanques sépticos coletivos e resíduos sólidos orgânicos domiciliares. Campina Grande-PB. Novembro de 2006 a fevereiro de 2007.

A aeração dos reatores ocorreu com periodicidade, três vezes por semana, em dias previamente definidos (terça-feira, quinta-feira e sábado) e consistiu de reviramento manual dos substratos, utilizando-se de instrumentos agrícolas adaptados (estrovenga, pá e cabo de enxada). O reviramento foi executado após a aferição da temperatura. A coleta das amostras para as análises semanais ocorreu no momento do reviramento. Os parâmetros analisados e os métodos aplicados são apresentados por meio do Quadro 2.

Quadro 2. Método e frequência de análise dos parâmetros físico, químicos e biológicos dos diferentes tratamentos de co-compostagem de lodos de tanques sépticos coletivos e resíduos sólidos orgânicos domiciliares. Campina Grande-PB. Novembro de 2006 a fevereiro de 2007.

\begin{tabular}{|c|c|c|}
\hline Parâmetros & Frequência & Método Utilizado \\
\hline Temperatura & Diária & Termômetro de mercúrio \\
Umidade (\%) & Semanal & Gravimétrico \\
pH (unidade) & Semanal & Potenciométrico \\
Sólidos Totais voláteis-STV (\%ST) & Semanal & Gravimétrico \\
Carbono orgânico Total-COT (\%ST) & Semanal & Kiehl (1998) \\
Nitrogênio Kjedahl - NTK (\%ST) & Semanal & Método Kjeldhal com digestão. \\
Fósforo Total -P(\%ST) & Semanal & Espectrofotométrico com ácido ascórbico \\
& e digestão em persulfato de amônio \\
Potássio-K(\%) & Semanal & Fotometria de chama \\
Ovos de helmintos (ovos/gST) & Semanal & Meyer (1978) modificado \\
\hline
\end{tabular}

Para a conclusão dos experimentos executou-se o peneiramento duplo da massa final e a classificação do composto de acordo com a Normativa n. 23 de 31 de agosto de 2005 do Ministério da Agricultura, Pecuária e Abastecimento (Brasil, 2005). No primeiro momento, utilizou-se uma peneira de $4 \mathrm{~mm}$, em seguida, uma peneira de $2 \mathrm{~mm}$; tendo como produto final dois tipos de composto: farelo e pó (Brasil, 2005), além do rejeito.

\subsection{Análise Estatística}

Para testar a homogeneidade entre as variâncias utilizou-se o teste de Levene. A ocorrência de variância entre os diferentes tratamentos foi avaliada aplicando-se o teste de Tukey.

Os dados descritos neste trabalho foram apresentados e analisados tomando-se por base a média aritmética das repetições para cada tratamento. O grau de dispersão mostrou-se baixo (Desvio padrão) (Santos e Gheyi, 2003). 
SILVA, M. M. P.; SOUZA, J. T.; CEBALlOS, B. S. O.; FEITOSA, W. B. S.; LEITE, V. D. Tratamento aeróbio conjugado de lodos de tanques sépticos e resíduos sólidos orgânicos domiciliares. Ambi-Agua, Taubaté, v. 4, n. 3, p. 123-143, 2009. (doi:10.4136/ambi-agua.107)

\section{RESULTADOS E DISCUSSÃO}

\subsection{Características dos lodos de tanques sépticos e dos resíduos sólidos orgânicos domiciliares}

Considerando-se os valores mínimos e máximos dos parâmetros investigados em lodos de tanques sépticos coletivos localizados em Cabaceiras, Caraúbas e Queimadas (Tabela 2), observou-se alto grau de dispersão, explicado pelas diferenças observadas da composição dos lodos nas diferentes câmaras. Essas diferenças, principalmente nas primeiras câmaras, podem ser justificadas pela variação da vazão dos esgotos ao longo do sistema, pelo tempo de detenção, pelo nível de turbulência hidráulica em cada câmara e, por último, devido às falhas observadas no pré-tratamento (gradeamento e caixa de areia), este último ocasionando o assoreamento da primeira câmara nos tanques sépticos de Caraúbas e Queimadas e na primeira e segunda câmaras do tanque séptico de Cabaceiras, reduzindo a eficiência na remoção de sólidos sedimentáveis, consequentemente, de sólidos totais voláteis nessas câmaras. Essa constatação motivou a opçao de não utilizar para montagem do experimento, os lodos das primeiras câmaras dos tanques sépticos estudados.

Tabela 2. Características dos lodos originados das diferentes câmaras dos tanques sépticos coletivos dos municípios de Cabaceiras, Caraúbas e Queimadas - PB. Agosto a novembro de 2006.

\begin{tabular}{|c|c|c|c|c|c|c|c|c|c|c|}
\hline Município & Câmara & $\mathbf{p H}$ & $\begin{array}{c}\text { Umidade } \\
(\%)\end{array}$ & $\begin{array}{c}\text { STV } \\
(\% \text { ST) }\end{array}$ & $\begin{array}{l}\text { COT } \\
(\% S T)\end{array}$ & $\begin{array}{c}\text { NTK } \\
(\% S T)\end{array}$ & $\mathrm{C} / \mathrm{N}$ & $\begin{array}{c}\text { P } \\
(\% S T)\end{array}$ & $\begin{array}{c}\mathrm{K} \\
(\% \mathrm{ST})\end{array}$ & $\begin{array}{c}\text { Helmintos } \\
\text { (ovos } \\
\text { viáveis/gST) }\end{array}$ \\
\hline \multirow[t]{8}{*}{ Cabaceiras } & 1 & 7,2 & 49,6 & 12,1 & 6,7 & 0,6 & 11,2 & 0,5 & 0,1 & 2,4 \\
\hline & 2 & 6,7 & 67,4 & 15,5 & 8,6 & 1,4 & 6,1 & 0,4 & 0,1 & 13,7 \\
\hline & 3 & 7,4 & 72,2 & 23,2 & 12,9 & 0,6 & 21,1 & 0,4 & 0,1 & 13,8 \\
\hline & 4 & 7,1 & 75,9 & 23,1 & 12,8 & 0,6 & 21,3 & 0,4 & 0,1 & 19,9 \\
\hline & 5 & 7,2 & 83,1 & 39,7 & 22,1 & 1,8 & 12,2 & 0,7 & 0,1 & 74,7 \\
\hline & 6 & 7,2 & 83,9 & 40,4 & 22,5 & 1,8 & 12,2 & 0,8 & 0,1 & 113,2 \\
\hline & 7 & 6,9 & 86,7 & 44,0 & 24,4 & 1,8 & 13,7 & 0,6 & 0,1 & 127,2 \\
\hline & 8 & 7,0 & 88,2 & 43,6 & 24,2 & 2 & 12,1 & 0,6 & 0,1 & 9,0 \\
\hline \multirow[t]{3}{*}{ Caraúbas } & 1 & 6,9 & 28,5 & 3,5 & 2,0 & 0,3 & 6,6 & 0,3 & 0,1 & 1,3 \\
\hline & 2 & 7,2 & 86,3 & 41,6 & 23,1 & 2,3 & 9,9 & 0,7 & 0,1 & 287,1 \\
\hline & 3 & 7,3 & 88,7 & 43,7 & 24,3 & 2,6 & 9,2 & 0,7 & 0,1 & 345,1 \\
\hline \multirow[t]{6}{*}{ Queimadas } & 1 & NA & NA & NA & NA & NA & NA & NA & NA & NA \\
\hline & 2 & 7,2 & 70,2 & 19,8 & 11,0 & 0,9 & 12,9 & 0,6 & 0,1 & 17,5 \\
\hline & Mínimo & 6,7 & 28,5 & 3,5 & 2,0 & 0,3 & 6,1 & 0,3 & 0,1 & 1,3 \\
\hline & Máximo & 7,4 & 88,7 & 44 & 24,4 & 2,6 & 21,3 & 0,8 & 0,1 & 345,1 \\
\hline & Média & 7,1 & 73,4 & 29,2 & 16,2 & 1,4 & 12,4 & 0,6 & 0,1 & 85,4 \\
\hline & DP & 0,2 & 18,2 & 14,5 & 8,1 & 0,8 & 4,8 & 0,2 & 0,0 & 116,7 \\
\hline
\end{tabular}

ST: Sólidos totais; STV: Sólidos totais voláteis; COT: Carbono orgânico total; C: Carbono; N: Nitrogênio; NTK: Nitrogênio Kjeldahl; P: Fósforo; K: Potássio. DP: Desvio Padrão; NA: Não analisado.

A péssima qualidade sanitária dos lodos dos tanques sépticos coletivos representada pelo valor médio de ovos de helmintos viáveis (85,4 ovos viáveis/gST) reafirma a necessidade de tratamento, antes da destinação final. As características físicas e químicas ratificam a potencialidade para compostagem, como alternativa tecnológica de tratamento. Todavia, o teor médio de umidade $(73,4 \%)$ e de sólidos totais volatéis $(29,2 \% \mathrm{ST})$, a baixa relação C/N $(12,4)$ e a granulometria desses resíduos impuseram a adição de outro tipo de resíduos sólidos orgânicos, escolhendo-se os domiciliares.

Os resíduos sólidos orgânicos domiciliares coletados nos municípios de Cabaceiras, Caraúbas e Queimadas, embora coletados na fonte geradora (residências) também apresentaram péssima qualidade sanitária (13,13 ovos viáveis/gST) (Tabela 3). Por 
SILVA, M. M. P.; SOUZA, J. T.; CEBALlOS, B. S. O.; FEITOSA, W. B. S.; LEITE, V. D. Tratamento aeróbio conjugado de lodos de tanques sépticos e resíduos sólidos orgânicos domiciliares. Ambi-Agua, Taubaté, v. 4, n. 3, p. 123-143, 2009. (doi:10.4136/ambi-agua.107)

conseguinte, a co-compostagem representou uma possibilidade de tratar simultaneamente lodos de tanques sépticos coletivos e resíduos sólidos orgânicos domiciliares, ambos, considerados importantes fontes de poluição e de contaminação quando não são destinados adequadamente.

Os resíduos sólidos orgânicos domiciliares coletados apresentaram caracteristicas propícias à co-compostagem com lodos de tanques sépticos (Tabela 3): sólidos totais voláteis (78,94\%ST), relação C/N (21,5), textura e granulometria apropriadas. Entretanto, o teor médio de umidade $(75,27 \%)$ indicou a necessidade de estruturante (folhas) para iniciar o processo de co-compostagem com teor de umidade próximo à faixa indicada na literatura (5560\%) conforme indicação de Neklyudov et al., (2008) e Ogunwande et al. (2008b). O percentual de estruturante (folhas) empregado correspondeu a 10\% dos resíduos sólidos orgânicos domiciliares utilizado para cada tratamento.

Tabela 3. Caracterização física e química dos resíduos sólidos orgânicos domiciliares gerados na área urbana de Cabaceiras, Caraúbas e Queimadas - PB. Setembro a novembro de 2006.

\begin{tabular}{|c|c|c|c|c|c|c|c|c|c|}
\hline Municípios & pH & $\begin{array}{c}\text { Umidade } \\
\text { (\%) }\end{array}$ & $\begin{array}{c}\text { STV } \\
(\% S T)\end{array}$ & $\begin{array}{c}\text { COT } \\
(\% S T)\end{array}$ & $\begin{array}{c}\text { NTK } \\
\text { (\%ST) }\end{array}$ & $\mathrm{C} / \mathrm{N}$ & $\begin{array}{c}\text { P } \\
(\% \mathrm{ST})\end{array}$ & $\begin{array}{c}\mathrm{K} \\
(\% \mathrm{ST})\end{array}$ & $\begin{array}{c}\text { Helmintos } \\
\text { (ovos } \\
\text { viáveis/gST) }\end{array}$ \\
\hline Cabaceiras & 4,83 & 78,82 & 82,59 & 45,88 & 2,03 & 22,73 & 0,16 & 0,11 & 12,82 \\
\hline Caraúbas & 5,17 & 77,06 & 81,48 & 45,26 & 2,66 & 18,79 & 0,42 & 0,12 & 14,39 \\
\hline Queimadas & 5,19 & 69,94 & 72,76 & 40,42 & 1,89 & 22,99 & 0,30 & 0,12 & 12,19 \\
\hline Média & 5,06 & 75,27 & 78,94 & 43,85 & 2,19 & 21,50 & 0,29 & 0,12 & 13,13 \\
\hline DP & 0,20 & 4,70 & 5,38 & 2,99 & 0,41 & 2,35 & 0,13 & 0,01 & 1,13 \\
\hline
\end{tabular}

ST: Sólidos totais; STV: Sólidos totais voláteis; COT: Carbono orgânico total; C: Carbono; N: Nitrogênio; NTK: Nitrogênio Kjeldahl; P: Fósforo; K: Potássio; n=3; DP: Desvio Padrão.

\subsection{Co-compostagem de lodos de tanques sépticos coletivos com resíduos sólidos orgânicos domiciliares}

A co-compostagem, como processo aeróbio de degradação biológica de lodos de tanques sépticos coletivos e resíduos sólidos orgânicos domiciliares, requer o controle de parâmetros físicos e químicos, de forma a possibilitar a ação dos organismos autóctones e garantir um produto final estabilizado, higienizado e com características agronômicas adequadas ao seu reaproveitamento no solo e na vegetação da região semiárida.

O controle da compostagem deve ocorrer em todas as etapas do processo tecnológico: pré-tratamento, tratamento e pós-tratamento. O pré-tratamento envolve a definição da composição do substrato, coleta, seleção e aspectos granulométricos, a observação do teor de umidade e da relação $\mathrm{C} / \mathrm{N}$ ideal. $\mathrm{O}$ controle do teor de umidade na massa inicial foi tão importante quanto o da relação $\mathrm{C} / \mathrm{N}$. O emprego de estruturante recomendado na literatura (Banegas et al., 2007; Adhikari et al., 2008; Lu et al., 2008), propiciou espaços de aeração entre as partículas que constituíam os lodos e permitiram a superação do limite do uso de lodos de esgotos, em relação à granulometria.

Os teores de umidade iniciais entre 55,03 a 58,17\% (Figura 2), faixa considerada ótima (Neklyudov et al., 2008; Ogunwande et al., 2008a) favoreceram a ação dos organismos e a consequentemente, liberação de calor, aumentando a temperatura em níveis ideais à destruição e à inviabilização de ovos de helmintos $\left(45-65^{\circ} \mathrm{C}\right)$, conforme sugerem Correa et al., (2007), USEPA (2003) e Carrington (2001).

Ao longo da co-compostagem ocorreu redução gradativa do teor de umidade, resultando em compostos com teores de umidade entre 31 e 38\%. Na base dos reatores foram encontrados os maiores teores, em virtude da menor oxigenação.

A concentração de STV na massa inicial decresceu em função da fração de lodos de tanques sépticos. No processo de estabilização, em todos os tratamentos, houve a diminuição 
SILVA, M. M. P.; SOUZA, J. T.; CEBALlOS, B. S. O.; FEITOSA, W. B. S.; LEITE, V. D. Tratamento aeróbio conjugado de lodos de tanques sépticos e resíduos sólidos orgânicos domiciliares. Ambi-Agua, Taubaté, v. 4, n. 3, p. 123-143, 2009. (doi:10.4136/ambi-agua.107)

gradativa dos STV, atingindo reduções de 43,92 a 57,61\% em 91 dias (Tabela 4). O menor percentual correspondeu ao tratamento 4 (T4), provavelmente, devido às menores concentrações de STV (41,87\%) e COT $(23,26 \%)$ e menor relação C/N $(17,81)$ na massa inicial, que limitou a ação biodegradadora dos organismos e resultou em menores níveis de temperatura.

Tabela 4. Valores médios relativos aos parâmetros STV, COT e C/N para os diferentes tratamentos de cocompostagem de lodos de tanques sépticos com resíduos sólidos orgânicos domiciliares. Campina GrandePB. Novembro de 2006 a fevereiro de 2007.

\begin{tabular}{c|cccc|ccccc|cccc}
\hline \multirow{2}{*}{$\begin{array}{c}\text { Tempo } \\
\text { (Semana) }\end{array}$} & \multicolumn{4}{|c|}{ STV(\%ST) } & \multicolumn{4}{c|}{ COT(\%ST) } & \multicolumn{4}{c}{ C/N } \\
\hline & T1 & T2 & T3 & T4 & T1 & T2 & T3 & T4 & T1 & T2 & T3 & T4 \\
\hline $\mathbf{0}$ & 49,58 & 47,31 & 46,01 & 41,87 & 27,49 & 26,29 & 25,56 & 23,26 & 19,22 & 18,21 & 19,08 & 17,81 \\
$\mathbf{1}^{\mathbf{a}}$ & 43,84 & 45,95 & 43,76 & 43,09 & 24,36 & 25,53 & 24,31 & 23,94 & 20,65 & 18,00 & 19,42 & 17,35 \\
$\mathbf{2}^{\mathbf{a}}$ & 44,11 & 41,70 & 42,61 & 37,96 & 24,51 & 23,17 & 23,67 & 21,09 & 18,81 & 18,24 & 16,23 & 14,33 \\
$\mathbf{3}^{\mathbf{a}}$ & 40,58 & 37,72 & 41,54 & 37,31 & 22,54 & 20,96 & 23,08 & 20,73 & 16,65 & 14,31 & 15,46 & 14,06 \\
$\mathbf{4}^{\mathbf{a}}$ & 39,31 & 34,92 & 35,31 & 32,62 & 21,19 & 19,40 & 19,62 & 18,12 & 11,79 & 11,56 & 14,14 & 13,26 \\
$\mathbf{5}^{\mathbf{a}}$ & 35,84 & 34,57 & 34,59 & 33,51 & 19,91 & 19,20 & 19,22 & 18,62 & 12,14 & 9,52 & 12,63 & 9,70 \\
$\mathbf{6}^{\mathbf{a}}$ & 29,05 & 32,03 & 31,26 & 30,23 & 16,14 & 17,79 & 17,37 & 16,80 & 10,13 & 9,78 & 9,94 & 9,39 \\
$\mathbf{7}^{\mathbf{a}}$ & 31,20 & 30,28 & 31,42 & 33,30 & 17,34 & 16,82 & 17,45 & 18,50 & 10,77 & 10,64 & 11,77 & 12,46 \\
$\mathbf{8}^{\mathbf{a}}$ & 31,77 & 34,53 & 32,67 & 31,48 & 17,65 & 19,19 & 18,15 & 17,49 & 11,78 & 12,48 & 11,78 & 11,59 \\
$\mathbf{9}^{\mathbf{a}}$ & 29,84 & 27,98 & 27,58 & 26,43 & 16,58 & 15,54 & 15,32 & 14,68 & 9,58 & 8,83 & 9,84 & 9,34 \\
$\mathbf{1 0}^{\mathbf{a}}$ & 29,16 & 30,02 & 29,72 & 28,41 & 16,20 & 16,68 & 16,51 & 15,78 & 11,46 & 10,19 & 9,41 & 9,63 \\
$\mathbf{1 1}^{\mathbf{a}}$ & 29,33 & 29,41 & 29,88 & 30,32 & 16,29 & 16,34 & 16,6 & 16,84 & 8,52 & 8,56 & 8,02 & 7,60 \\
$\mathbf{1 2}^{\mathbf{a}}$ & 29,07 & 29,26 & 28,58 & 27,06 & 16,15 & 16,26 & 15,88 & 15,03 & 8,20 & 7,34 & 7,86 & 6,80 \\
$\mathbf{1 3}^{\mathbf{a}}$ & 25,86 & 27,08 & 27,72 & 27,57 & 14,37 & 15,04 & 15,40 & 15,31 & 6,84 & 6,53 & 6,68 & 7,02 \\
\hline
\end{tabular}

COT: Carbono orgânico Total; STV: sólidos totais volatéis; $n=3$.

Mohee et al. (2008), avaliando o processo de co-compostagem de resíduos de granja e aparas de papel nas Ilhas Maurícius com relação C/N de 20,8, alcançaram a redução média de STV de 56,7\%, no final da quinta semana, valores próximos aos obtidos para os tratamentos 1 e 2. Tognetti et al. (2007), investigando a co-compostagem de lodos de esgotos com resíduos sólidos orgânicos municipais na Argentina nas proporções: 50\%, 30\% e 25\% de lodos registraram a redução de STV de 39\% e 45\% em 120 dias. Neste trabalho, observa-se o aumento do tempo de estabilização e o menor percentual de redução de STV, possivelmente, em função da maior proporção de lodos de esgotos.

Em processo de estabilização considerado eficiente, a USEPA (1993) recomenda redução superior a 38\% para biossólidos Classe A. Os percentuais de redução obtidos, decrescentes em função do aumento da fração de lodos (43,92 a 57,61\%) retratam a eficiência do processo de estabilização em todos os tratamentos (T1, T2, T3, e T4) (Tabela 4). Com base na Resolução 375/06 do CONAMA (Brasil, 2006a), que determina a relação de 0,70 de STV e ST para que os lodos de esgotos ou produtos derivados sejam considerados estáveis e utilizados na agricultura, conclui-se que em todos os tratamentos do presente trabalho, os compostos podem ser considerados estáveis (Tabela 5).

Nos diferentes tratamentos, a redução para COT variou de $44,02 \%$ a 57,63\% e seguiu o acréscimo da fração de lodos de tanques sépticos (Tabela 4).

Em todos os tratamentos, a relação $\mathrm{C} / \mathrm{N}$ inicial esteve abaixo da faixa considerada ideal (25:1 e 30:1) por Ogunwande et al. (2008a); Correa et al. (2007), Hoornweg et al., (2000) e próxima da relação C/N (20:1) sugerida por Neklyuodv et al. (2008) e Mohee et al. (2008). Não foram verificadas diferenças significativas em função da fração de lodos de tanques sépticos. O declínio da relação $\mathrm{C} / \mathrm{N}$ acompanhou a diminuição dos teores de umidade, demonstrando a interdependência entre os dois parâmetros $(\mathrm{r}=0,71)$ e reforçando a importância do controle inicial do teor de umidade para o processo de estabilização. Constata- 
SILVA, M. M. P.; SOUZA, J. T.; CEBALlOS, B. S. O.; FEITOSA, W. B. S.; LEITE, V. D. Tratamento aeróbio conjugado de lodos de tanques sépticos e resíduos sólidos orgânicos domiciliares. Ambi-Agua, Taubaté, v. 4, n. 3, p. 123-143, 2009. (doi:10.4136/ambi-agua.107)

se que a relação C/N inicial entre 17,8:1 a 19,2:1 não prejudicou a eficiência dos reatores em relação à elevação da temperatura, à inativação de ovos de helmintos e ao composto resultante. De acordo com a Instrução Normativa 23/2005 (Brasil, 2005), os compostos devem apresentar relação $\mathrm{C} / \mathrm{N}$ de 8 a 12. Os compostos dos diferentes tratamentos obtidos no presente trabalho enquadram-se na faixa citada $(10,2: 1$ a $12,6: 1)$.

Tabela 5. Valores médios relativos ao coeficiente STV/ST para os diferentes tratamentos de co-compostagem de lodos de tanques sépticos com resíduos sólidos orgânicos domiciliares. Campina Grande-PB. Novembro de 2006 a fevereiro de 2007.

\begin{tabular}{c|cccc}
\hline \multirow{2}{*}{$\begin{array}{c}\text { Tempo } \\
\text { (Semana) }\end{array}$} & \multicolumn{4}{|c}{ Coeficiente STV/ST } \\
\cline { 2 - 5 } T1 & T2 & T3 & T4 \\
\hline 0 & 1,12 & 1,04 & 1,04 & 0,97 \\
$1^{\mathrm{a}}$ & 0,84 & 0,99 & 0,94 & 0,96 \\
$2^{\mathrm{a}}$ & 0,83 & 0,74 & 0,78 & 0,72 \\
$3^{\mathrm{a}}$ & 0,73 & 0,71 & 0,80 & 0,71 \\
$4^{\mathrm{a}}$ & 0,73 & 0,64 & 0,64 & 0,60 \\
$5^{\mathrm{a}}$ & 0,62 & 0,57 & 0,60 & 0,55 \\
$6^{\mathrm{a}}$ & 0,54 & 0,62 & 0,60 & 0,58 \\
$7^{\mathrm{a}}$ & 0,56 & 0,54 & 0,56 & 0,6 \\
$8^{\mathrm{a}}$ & 0,64 & 0,75 & 0,65 & 0,63 \\
$9^{\mathrm{a}}$ & 0,55 & 0,50 & 0,52 & 0,47 \\
$10^{\mathrm{a}}$ & 0,50 & 0,50 & 0,53 & 0,49 \\
$11^{\mathrm{a}}$ & 0,50 & 0,51 & 0,53 & 0,54 \\
$12^{\mathrm{a}}$ & 0,48 & 0,48 & 0,48 & 0,44 \\
$13^{\mathrm{a}}$ & 0,39 & 0,41 & 0,43 & 0,41 \\
\hline
\end{tabular}

DQO: Demanda Química de Oxigênio; STV: Sólidos totais volatéis; ST: Sólidos totais.

Para os nutrientes NTK, fósforo e potássio não foram observadas diferenças significativas em função da fração dos lodos de tanques sépticos nos diferentes tratamentos (Tabela 6). De acordo com os autores Singh e Agrawal (2008), Agustini e Onofre (2007), Summerfelt e Penne (2007), o conteúdo de nitrogênio e fósforo nos lodos de esgotos justificam a sua aplicação agrícola. O uso de resíduos sólidos orgânicos domiciliares em cocompostagem, segundo Koné et al. (2007) favorece o equilíbrio da relação $\mathrm{C} / \mathrm{N}$, pois estes detêm menor concentração de nitrogênio. No caso dos lodos utilizados nos diferentes tratamentos, o valor médio de NTK $(1,4 \% S T)$ foi inferior ao dos resíduos orgânicos domiciliares (2,2\%ST). Fato semelhante ocorreu com a concentração de potássio (Tabela 6).

Considerando os ST, os percentuais de NTK e de fósforo aumentaram durante a cocompostagem gradativamente nos diferentes tratamentos (Tabela 6), diferente da concentração de COT que se perde, principalmente na forma de $\mathrm{CO}_{2}$. A transformação NTK e fósforo da forma orgânica para inorgânica, não significa em perda significativa para o sistema (Kiehl, 1998). A ausência de produção de chorume, também evitou a perda desses nutrientes por lixiviação.

Os valores médios de fósforo total na massa final de todos os tratamentos $(0,30 \mathrm{a}$ 0,41\%ST) (Tabela 6) foram próximos aos identificados por Barreira et al. (2006), ao analisar compostos orgânicos de 16 usinas de compostagem situadas no estado de São Paulo (0,027 a $0,48 \% \mathrm{ST}$ ) e inferiores ao teor obtido por Mohee, Mudhoo e Unmar (2008) na cocompostagem de aparas de papel de escritório com resíduos orgânicos de granja (5\%ST); superiores ao teor de fósforo nos compostos gerados a partir de compostagem de lodos, em Victória, Austrália, (0,24\%ST) por Correa et al. (2005), de co-compostagem de esterco de galinha com pó de serra $(0,27 \% S T)$ por Ogunwande et al. (2008a) na Nigéria. Os percentuais de potássio foram inferiores aos registrados por Mohee et al. (2008) (10\%ST) e por Ogunwande et al. (2008a) (0,23\%ST). Esses dados refletem a composição inicial do substrato 
SILVA, M. M. P.; SOUZA, J. T.; CEBALlOS, B. S. O.; FEITOSA, W. B. S.; LEITE, V. D. Tratamento aeróbio conjugado de lodos de tanques sépticos e resíduos sólidos orgânicos domiciliares. Ambi-Agua, Taubaté, v. 4, n. 3, p. 123-143, 2009. (doi:10.4136/ambi-agua.107)

e reafirmam a importância da co-compostagem de lodos de tanques sépticos para a reciclagem desses nutrientes.

Tabela 6. Valores médios de NTK, fósforo total e potássio total para os diferentes tratamentos de cocompostagem de lodos de tanques sépticos com resíduos sólidos orgânicos domiciliares expressos em ST. Campina Grande-PB. Novembro de 2006 a fevereiro de 2007.

\begin{tabular}{|c|c|c|c|c|c|c|c|c|c|c|c|c|}
\hline \multirow[b]{2}{*}{ Tempo (semana) } & \multicolumn{4}{|c|}{ NTK (\%ST) } & \multicolumn{4}{|c|}{$P(\% S T)$} & \multicolumn{4}{|c|}{$\mathrm{K}(\% \mathrm{ST})$} \\
\hline & T1 & $\mathbf{T} 2$ & T3 & T4 & T1 & $\mathbf{T} 2$ & T3 & T4 & T1 & T2 & T3 & T4 \\
\hline Instalação & 1,44 & 1,45 & 1,35 & 1,31 & 0,12 & 0,12 & 0,09 & 0,15 & 0,04 & 0,04 & 0,04 & 0,04 \\
\hline $1^{\mathrm{o}}$ & 1,19 & 1,43 & 1,25 & 1,38 & 0,16 & 0,18 & 0,17 & 0,20 & 0,04 & 0,04 & 0,04 & 0,04 \\
\hline $2^{\circ}$ & 1,31 & 1,27 & 1,46 & 1,47 & 0,22 & 0,24 & 0,24 & 0,24 & 0,04 & 0,04 & 0,03 & 0,03 \\
\hline $3^{a}$ & 1,36 & 1,46 & 1,53 & 1,47 & 0,22 & 0,23 & 0,22 & 0,24 & 0,03 & 0,03 & 0,03 & 0,03 \\
\hline $4^{\mathrm{a}}$ & 1,72 & 1,71 & 1,43 & 1,38 & 0,22 & 0,22 & 0,22 & 0,22 & 0,03 & 0,03 & 0,03 & 0,03 \\
\hline $5^{a}$ & 1,64 & 2,02 & 1,60 & 1,93 & 0,23 & 0,22 & 0,20 & 0,21 & 0,03 & 0,04 & 0,04 & 0,03 \\
\hline $6^{\mathrm{a}}$ & 1,60 & 1,83 & 1,75 & 1,79 & 0,23 & 0,22 & 0,19 & 0,20 & 0,03 & 0,02 & 0,03 & 0,03 \\
\hline $7^{\mathrm{a}}$ & 1,62 & 1,58 & 1,50 & 1,50 & 0,24 & 0,22 & 0,18 & 0,19 & 0,03 & 0,04 & 0,04 & 0,04 \\
\hline $8^{a}$ & 1,50 & 1,54 & 1,55 & 1,51 & 0,24 & 0,23 & 0,17 & 0,18 & 0,04 & 0,04 & 0,04 & 0,04 \\
\hline $9^{a}$ & 1,73 & 1,77 & 1,57 & 1,58 & 0,25 & 0,22 & 0,18 & 0,17 & 0,04 & 0,04 & 0,04 & 0,03 \\
\hline $10^{\mathrm{a}}$ & 1,42 & 1,64 & 1,76 & 1,64 & 0,27 & 0,25 & 0,23 & 0,21 & 0,05 & 0,04 & 0,03 & 0,03 \\
\hline $11^{\mathrm{a}}$ & 1,92 & 1,94 & 2,08 & 2,21 & 0,28 & 0,28 & 0,29 & 0,28 & 0,04 & 0,03 & 0,04 & 0,04 \\
\hline $12^{\mathrm{a}}$ & 1,97 & 2,23 & 2,03 & 2,22 & 0,30 & 0,30 & 0,31 & 0,34 & 0,02 & 0,02 & 0,02 & 0,02 \\
\hline $13^{\mathrm{a}}$ & 2,11 & 2,30 & 2,40 & 2,38 & 0,30 & 0,33 & 0,35 & 0,41 & 0,02 & 0,02 & 0,02 & 0,02 \\
\hline
\end{tabular}

NTK: Nitrogênio Kjeldahl; P: Fósforo; K: Potássio.

Em todos os tratamentos, no primeiro dia de co-compostagem foi observado $\mathrm{pH}$ ácido (5,3 a 6,6), característico do início do processo de compostagem. Nas duas primeiras semanas foi constatado $\mathrm{pH}$ que denota a fase termófila para todos os tratamentos $(7,4$ a 9,7$)$, seguidose da fase de maturação, caracterizada por $\mathrm{pH}$ na faixa de 9,6 a 10,3. No final do processo, os compostos resultantes apresentaram pH entre 8,4 e 9,2 (Figura 2).

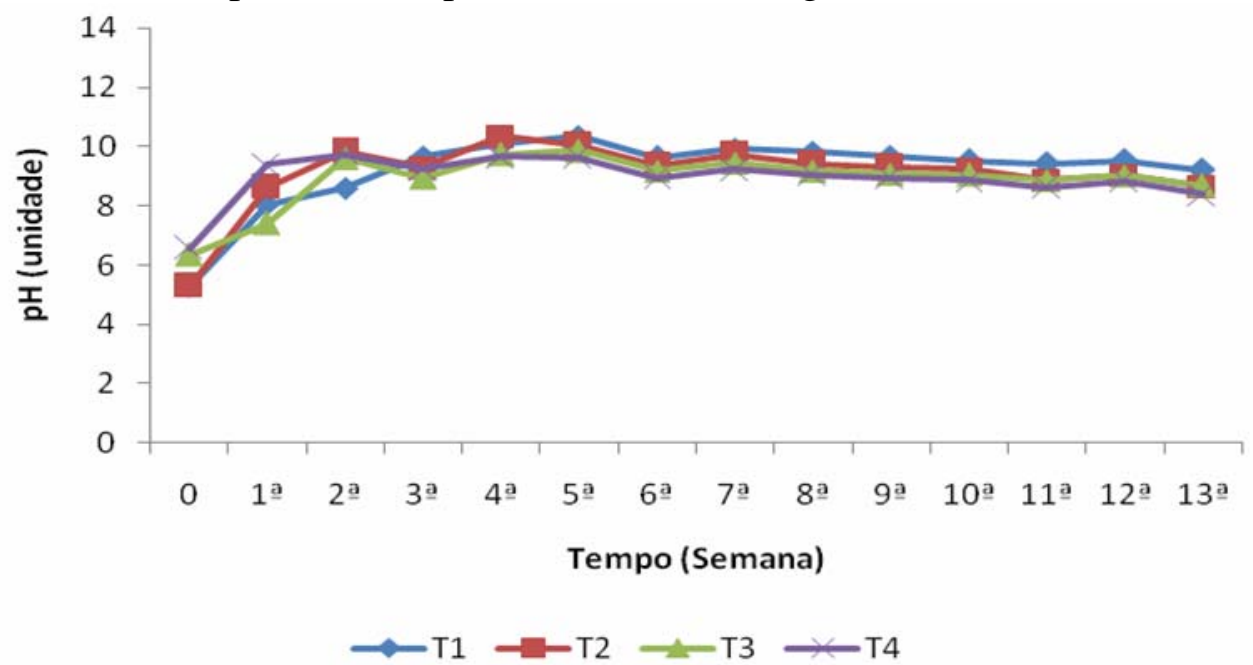

Figura 2. Níveis de $\mathrm{pH}$ para os diferentes tratamentos de co-compostagem de lodos de tanques sépticos com resíduos sólidos orgânicos domiciliares. Campina Grande-PB. Novembro de 2006 a fevereiro de 2007.

Na massa inicial, verificou-se elevação de pH à medida que aumentou a fração dos lodos de tanques sépticos (Figura 2). Comumente, os resíduos sólidos orgânicos domiciliares apresentam pH ácido (Tavares et al., 2007; Callaghan et al., 2002); o lodo primário apresenta 
SILVA, M. M. P.; SOUZA, J. T.; CEBALlOS, B. S. O.; FEITOSA, W. B. S.; LEITE, V. D. Tratamento aeróbio conjugado de lodos de tanques sépticos e resíduos sólidos orgânicos domiciliares. Ambi-Agua, Taubaté, v. 4, n. 3, p. 123-143, 2009. (doi:10.4136/ambi-agua.107)

pH próximo ao neutro (Correa et al., 2005), o que explica a elevação de pH em função da fração dos lodos.

A temperatura é uma das variáveis que indica a eficiência do sistema, no decorrer do processo de biodegradação pelos organismos, cujo metabolismo é exotérmico (Liang et al., 2003). Nesta pesquisa, a fase de adaptação foi bastante curta, não ultrapassando três horas. No primeiro dia de instalação do experimento, registraram-se valores de temperatura (45 a $65^{\circ} \mathrm{C}$ ) que caracterizaram a fase termófila (Figura 3). Esses valores na superfície e no centro do substrato foram mantidos em T1 durante 11 dias e em T2 e T3 por dez dias; já em T4 por seis dias (Figura 3). Os resultados expressam a diminuição do tempo de duração da fase termófila em função do aumento da fração dos lodos de tanques sépticos, explicado pela menor concentração de STV com o incremento desse resíduo.

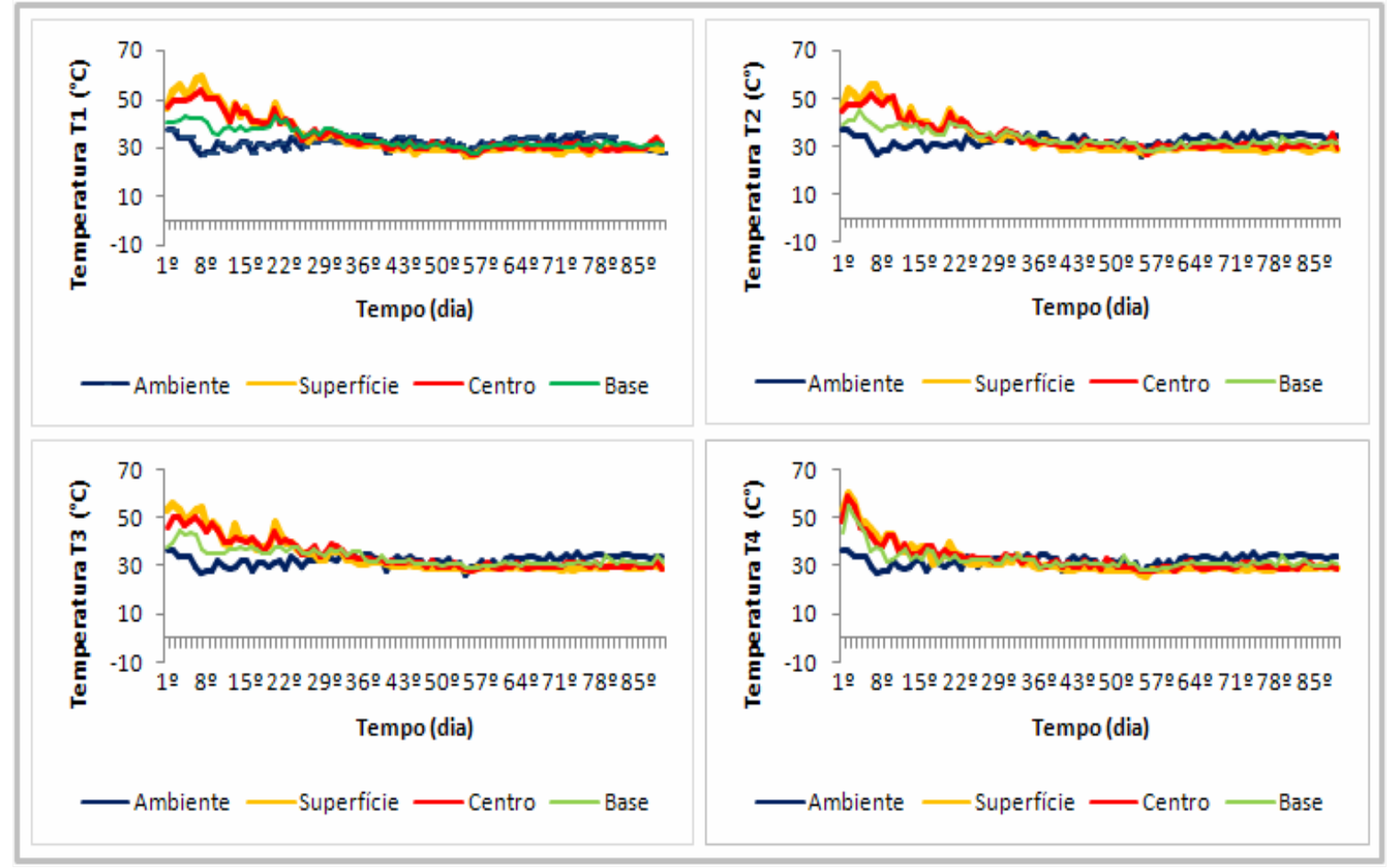

Figura 3. Valores médios diários de temperatura nos diferentes tratamentos (T1, T2, T3 e T4) de co-compostagem de lodos de tanques sépticos com resíduos sólidos orgânicos domiciliares. Campina Grande-PB. Novembro de 2006 a fevereiro de 2007.

Os maiores valores de temperatura foram observados na superfície e no centro da massa do substrato para os diferentes tratamentos (Figura 3). No tratamento 4 (T4), verificaram-se os maiores valores de temperatura, todavia, foi no tratamento 1 (T1), que as temperaturas termófilas se mantiveram durante maior tempo. Na massa inicial do tratamento 1 (T1) foram registradas as maiores concentrações de STV, 49,5\%ST, como também, a mais alta relação C/N, 19,2. Esses fatores, provavelmente, influenciaram no aumento do tempo de duração da fase termófila, diminuindo, consequentemente, o tempo necessário para a destruição de ovos de helmintos.

Sequenciando a fase termófila, ocorreu o declínio da temperatura de $45^{\circ} \mathrm{C}$ para $35^{\circ} \mathrm{C}$ (Figura 3), caracterizando o início da fase mesófila, que teve, em média, 12 dias de duração. Na quarta e última fase, maturação, os valores da temperatura foram próximos à temperatura ambiente. Esta foi a fase de maior duração (em torno de 54 dias). 
SILVA, M. M. P.; SOUZA, J. T.; CEBALlOS, B. S. O.; FEITOSA, W. B. S.; LEITE, V. D. Tratamento aeróbio conjugado de lodos de tanques sépticos e resíduos sólidos orgânicos domiciliares. Ambi-Agua, Taubaté, v. 4, n. 3, p. 123-143, 2009. (doi:10.4136/ambi-agua.107)

A concentração de ovos de helmintos verificada na massa inicial de co-compostagem para os diferentes tratamentos, aumentou em função da fração dos lodos de tanques sépticos (Tabela 7), ressaltando o nível de patogenicidade desses resíduos.

Constatou-se o decaimento da concentração de ovos de helmintos para 0,0 ovos/gST nos tratamentos, em períodos diferentes, caracterizando o aumento do tempo necessário à higienização em função da elevação da fração de lodos de tanques sépticos, conforme dados expostos na Tabela 7. Essa diferença teve relação com a fase termófila, a qual apresentou maior duração nos tratamentos com maior percentual de STV, COT e relação C/N. No tratamento 1, já na segunda semana não foram identificados ovos de helmintos. Nos tratamentos 2 e 3, a partir da quarta semana, não foram visualizados ovos de helmintos viáveis. No tratamento 4, a partir da sétima semana, no entanto, alguns ovos viáveis, foram identificados na décima primeira semana.

O reaparecimento de ovos de helmintos viáveis no tratamento 4 (Tabela 7), na décima primeira semana, possivelmente resultou dos menores valores de temperatura ocorridos na base do reator, ressaltando a importância do reviramento períodico, pois este, além de promover a aeração dos sistemas e favorecer a ação dos organismos autóctones aeróbios, propicia o transporte dos ovos de helmintos da base para a superfície, facilitando sua remoção. Provavelmente, na base dos reatores, os ovos de helmintos ficam mais protegidos, uma vez que esse ambiente funciona como isolante térmico, com pouca aeração, maior teor de umidade e maior probabilidade de formação de zonas de compactação, grumos.

Tabela 7. Valores médios de ovos de helmintos viáveis (V), não viáveis (NV) e totais (T) para os diferentes tratamentos de co-compostagem de lodos de tanques sépticos com resíduos sólidos orgânicos domiciliares. Campina Grande-PB. Novembro de 2006 a fevereiro de 2007.

\begin{tabular}{|c|c|c|c|c|c|c|c|c|c|c|c|c|}
\hline \multirow{3}{*}{ Tempo (Semana) } & \multicolumn{12}{|c|}{ Helmintos (Ovos/gST) } \\
\hline & \multicolumn{3}{|c|}{ T1 } & \multicolumn{3}{|c|}{ T2 } & \multicolumn{3}{|c|}{ T3 } & \multicolumn{3}{|c|}{ T4 } \\
\hline & $\mathbf{V}$ & NV & $\mathbf{T}$ & $\mathbf{V}$ & $\mathbf{N V}$ & $\mathbf{T}$ & $\mathbf{V}$ & $\mathbf{N V}$ & $\mathbf{T}$ & $\mathbf{V}$ & NV & $\mathbf{T}$ \\
\hline Instalação & 8,1 & 0,0 & 8,1 & 10,8 & 1,9 & 12,7 & 15,7 & 1,9 & 17,6 & 16,5 & 5,2 & 21,7 \\
\hline $1^{\mathrm{a}}$ & 6,1 & 0,8 & 6,9 & 10,7 & 4,7 & 15,4 & 7,6 & 4,8 & 12,4 & 12,9 & 0,0 & 12,9 \\
\hline $2^{\mathrm{a}}$ & 0,0 & 0,0 & 0,0 & 4,1 & 3,2 & 7,3 & 5,1 & 5,1 & 10,2 & 3,5 & 2,2 & 5,7 \\
\hline $3^{\mathrm{a}}$ & 0,0 & 0,0 & 0,0 & 7,1 & 4,2 & 11,3 & 6,3 & 4,9 & 11,2 & 8,4 & 3,2 & 11,6 \\
\hline $4^{\mathrm{a}}$ & 0,0 & 0,0 & 0,0 & 0,0 & 0,2 & 0,2 & 0,0 & 1,9 & 1,9 & 1,9 & 3,8 & 5,7 \\
\hline $5^{a}$ & 0,0 & 0,0 & 0,0 & 0,0 & 0,0 & 0,0 & 0,0 & 0,7 & 0,7 & 2,2 & 0,7 & 2,9 \\
\hline $6^{\mathrm{a}}$ & 0,0 & 0,0 & 0,0 & 0,0 & 0,0 & 0,0 & 0,0 & 0,0 & 0,0 & 0,7 & 0,8 & 1,5 \\
\hline $7^{\mathrm{a}}$ & 0,0 & 0,0 & 0,0 & 0,0 & 0,0 & 0,0 & 0,0 & 0,8 & 0,8 & 0,0 & 0,0 & 0,0 \\
\hline $8^{a}$ & 0,0 & 0,0 & 0,0 & 0,0 & 0,0 & 0,0 & 0,0 & 0,0 & 0,0 & 0,0 & 0,0 & 0,0 \\
\hline $9^{a}$ & 0,0 & 0,0 & 0,0 & 0,0 & 0,6 & 0,6 & 0,0 & 1,6 & 1,6 & 0,0 & 0,0 & 0,0 \\
\hline $10^{\mathrm{a}}$ & 0,0 & 0,0 & 0,0 & 0,0 & 0,0 & 0,0 & 0,0 & 0,0 & 0,0 & 0,0 & 0,0 & 0,0 \\
\hline $11^{\mathrm{a}}$ & 0,0 & 0,0 & 0,0 & 0,0 & 0,0 & 0,0 & 0,0 & 0,0 & 0,0 & 1,7 & 0,6 & 2,3 \\
\hline $12^{\mathrm{a}}$ & 0,0 & 0,0 & 0,0 & 0,0 & 0,0 & 0,0 & 0,0 & 1,0 & 1,0 & 0,0 & 0,0 & 0,0 \\
\hline $13^{\mathrm{a}}$ & 0,0 & 0,0 & 0,0 & 0,0 & 0,0 & 0,0 & 0,0 & 0,0 & 0,0 & 0,0 & 0,0 & 0,0 \\
\hline
\end{tabular}

V- Ovos viáveis; NV- Ovos não viáveis; T- Total de ovos de helmintos.

Verificou-se que a co-compostagem, além de permitir a estabilização dos lodos de tanques sépticos e resíduos sólidos orgânicos domiciliares, favoreceu a higienização destes , produzindo compostos isentos de ovos de helmintos, com qualidade sanitária segura, atendendo à legislação internacional e à nacional. Dessa forma, pelo parâmetro sanitário ovos de helmintos, os compostos produzidos nesta pesquisa podem ser enquadrados em composto classe A, conforme as Resoluções 375/06 e 380/06 do CONAMA (Brasil, 2006a; 
SILVA, M. M. P.; SOUZA, J. T.; CEBALlOS, B. S. O.; FEITOSA, W. B. S.; LEITE, V. D. Tratamento aeróbio conjugado de lodos de tanques sépticos e resíduos sólidos orgânicos domiciliares. Ambi-Agua, Taubaté, v. 4, n. 3, p. 123-143, 2009. (doi:10.4136/ambi-agua.107)

2006b). A eficiência de destruição dos ovos de helmintos correspondeu a 100\% para todos os tratamentos e para todos os tipos de helmintos identificados.

Entre os helmintos investigados, os ovos de Ascaris lumbricoides, mostraram-se os mais resistentes, seguindo a indicação da literatura. Os ovos de Ancylostoma sp. e Enterobius vermiculares foram destruídos mais facilmente. A literatura os considera os menos resistentes (Feachem et al., 1983). De acordo com Feachem et al. (1983), em temperaturas superiores a $40^{\circ} \mathrm{C}$, os ovos de Ancylostoma sp. são destruídos, enquanto que os de Enterobius vermiculares tendem a morrer em baixa umidade $(<34 \%)$. Os ovos de Fasciola hepatica desenvolvem-se na faixa de temperatura entre 25 a $37^{\circ} \mathrm{C}$, mas morrem rapidamente em baixa umidade e em ambiente com baixa concentração de matéria orgânica.

A ordem de destruição ou inativação de ovos de helmintos pode ser assim considerada: Ascaris lumbricoides, Fasciola hepatica, Trichuris trichiura, Taenea solium, Ancylostoma sp. e Enterobius vermiculares. Os ovos de Ascaris lumbricoides foram então, os mais resistentes, seguidos pelos ovos de Fasciola hepatica, de Trichuris trichiura e de Taenea solium. Os ovos de Ancylostoma sp. e Enterobius vermiculares foram os menos resistentes. Confirma-se a validade de ovos de Ascaris lumbricoides como indicador de qualidade sanitária em todos os biossólidos originados dos diferentes tratamentos de co-compostagem de lodos de tanques sépticos e resíduos sólidos orgânicos domiciliares preconizado na literatura internacional (USEPA, 2003; Metcalf e Eddy, 2003; Carrington, 2001). A resistência de ovos de Fasciola hepatica alerta para a urgência em ampliar os estudos sobre as condições de sobrevivência desse helminto.

As condições ambientais geradas de forma sequencial nos reatores durante o processo de co-compostagem, foram adversas à sobrevivência dos ovos de helmintos: redução do teor de umidade e de STV, temperaturas termófilas, $\mathrm{pH}$ alcalino e predatismo; permitindo não apenas a remoção de ovos de helmintos dos sistemas estudados, como também a inativação e a destruição dos mesmos. Os ovos inviáveis mostraram-se deformados, apresentando membrana externa danificada.

\subsection{Cinética de biodegradação durante o processo da compostagem}

A velocidade de biodegradação das diferentes frações dos lodos de tanques sépticos coletivos utilizados juntamente com os resíduos sólidos orgânicos domiciliares submetidos ao processo de compostagem pode ser representada por modelos matemáticos. Desta forma, as constantes de velocidade de biodegradação $(\mathrm{K})$ da concentração de sólidos totais voláteis e relação carbono/nitrogênio foram estimadas obedecendo à cinética de primeira ordem, sendo ajustadas as equações exponenciais aos dados obtidos semanalmente (Tabela 8).

Como as equações ajustadas para avaliar a biodegradação semanal da matéria orgânica expressam em termos de STV e o decaimento de C/N durante a co-compostagem de lodos de tanques sépticos com resíduos sólidos orgânicos domiciliares não apresentaram diferenças significativas em nível de probabilidade de 5\%, os dados estão apresentados em equação única para cada variável, conforme as Figuras 4 e 5.

O aumento da fração de lodos de tanques sépticos nos diferentes tratamentos reduziu a velocidade de biodegradação de STV $\left(\mathrm{K}_{\mathrm{STV}}=0,0095 \mathrm{dia}^{-1}\right.$ a 0,0069 dia $\left.^{-1}\right)$ durante o período de 91 dias (Tabela 11). A menor velocidade de biodegradação do substrato ocorreu no tratamento 4 (T4) $\left(\mathrm{K}_{\mathrm{STV}}=0,0069 \mathrm{dia}^{-1}\right)$, refletindo-se nas menores temperaturas no decorrer da co-compostagem; estas apresentaram diferença significativa em nível de 5\% de probabilidade dos demais tratamentos. As menores temperaturas aumentaram o tempo requerido para a destruição de ovos de helmintos, comparando-se aos demais tratamentos (T1, T2 e T3). 
SILVA, M. M. P.; SOUZA, J. T.; CEBALlOS, B. S. O.; FEITOSA, W. B. S.; LEITE, V. D. Tratamento aeróbio conjugado de lodos de tanques sépticos e resíduos sólidos orgânicos domiciliares. Ambi-Agua, Taubaté, v. 4, n. 3, p. 123-143, 2009. (doi:10.4136/ambi-agua.107)

Tabela 8. Equações de biodegradação ajustadas para os dados de STV e relação C/N obtidos semanalmente dos diferentes tratamentos de co-compostagem de lodos de tanques sépticos com resíduos sólidos orgânicos domiciliares. Campina Grande-PB. Novembro de 2006 a fevereiro de 2007.

\begin{tabular}{|c|c|c|c|c|}
\hline Tratamento & STV & $\overline{\mathbf{R}^{2}}$ & $\mathrm{C} / \mathrm{N}$ & $\mathbf{R}^{2}$ \\
\hline $\mathrm{T} 1$ & $\mathrm{STV}=10,0 \mathrm{e}^{-0,0095 t}$ & 0,8867 & $\mathrm{C} / \mathrm{N}=19,9 \mathrm{e}^{-0,0113 \mathrm{t}}$ & 0,9352 \\
\hline $\mathrm{T} 2$ & $S T V=9,6 e^{-0,0092 t}$ & 0,8774 & $\mathrm{C} / \mathrm{N}=18,5 \mathrm{e}^{-0,0109 t}$ & 0,9370 \\
\hline T3 & $S T V=9,7 e^{-0,0085 t}$ & 0,8871 & $\mathrm{C} / \mathrm{N}=18,9 \mathrm{e}^{-0,0107 \mathrm{t}}$ & 0,9687 \\
\hline $\mathrm{T} 4$ & $S T V=8,7 e^{-0,0069 t}$ & 0,8967 & $\mathrm{C} / \mathrm{N}=18,2 \mathrm{e}^{-0,0106 \mathrm{t}}$ & 0,9339 \\
\hline Valores médios & $S T V=9,5 e^{-0,0086 t}$ & 0,8959 & $C / N=18,9 e^{-0,0108 t}$ & 0,9635 \\
\hline
\end{tabular}

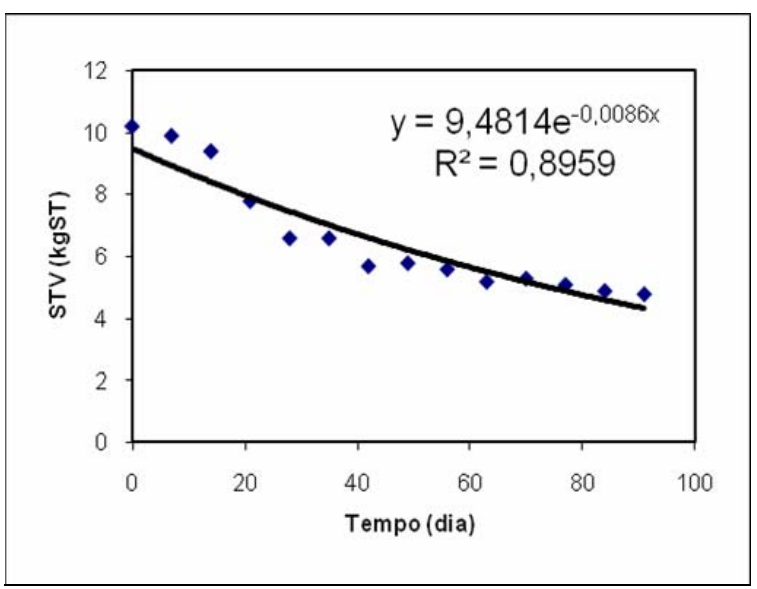

Figura 4. Equação geral de biodegradação de STV em 91 dias de co-compostagem de lodos de tanques sépticos com resíduos sólidos orgânicos domiciliares. Campina Grande-PB. Novembro de 2006 a fevereiro de 2007.

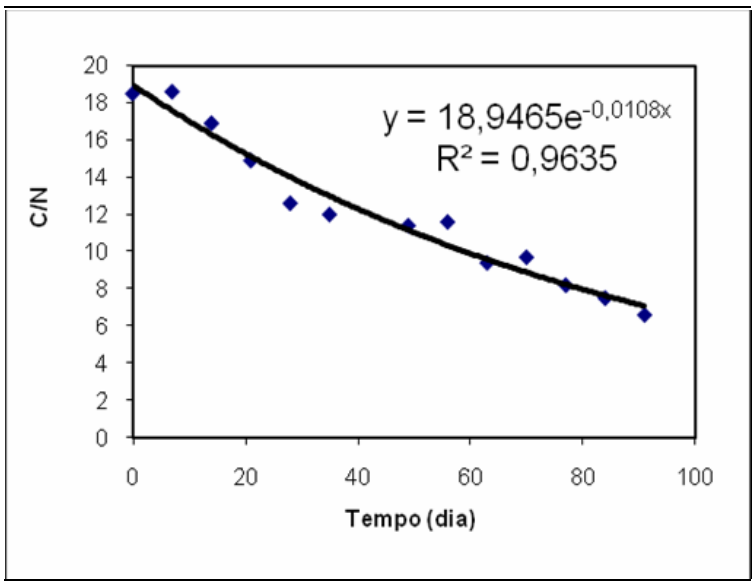

Figura 5. Equação geral de regressão de $\mathrm{C} / \mathrm{N}$ no período de 91 dias de co-compostagem de lodos de tanques sépticos com resíduos sólidos orgânicos domiciliares. Campina Grande-PB. Novembro de 2006 a fevereiro de 2007.

No final do processo não houve prejuízos para a qualidade do composto resultante desse tratamento. Por outro lado, em todos os tratamentos, a constante de degradação ( $\mathrm{K}_{\mathrm{STV}}$ ) apresentou-se maior do que as obtidas no trabalho de Matos et al. (1998) para a cocompostagem de diferentes resíduos orgânicos (bagaço de cana-de-açucar, capim napier, palhas de café) com esgotos de suinocultura $\left(\mathrm{K}_{\mathrm{c}}=0,002992 \mathrm{dia}^{-1}\right.$ a $\left.0,004327 \mathrm{dia}^{-1}\right)$, no perído de 90 a 133 dias. Esses resultados são indicativos que a co-compostagem de lodos de tanques sépticos coletivos com resíduos sólidos orgânicos domiciliares, além de permitir a estabilização e higienização desses resíduos, reduziu o tempo necessário à produção do composto.

\subsection{Qualidade dos compostos produzidos por co-compostagem}

As características físicas, químicas e sanitárias dos compostos resultantes dos diferentes tratamentos atenderam à Instrução Normativa n ${ }^{0} 23$ de 31 de agosto de 2005 do Ministério da Agricultura, Pecuária e Abastecimento para fertilizantes orgânicos (Brasil, 2005). Para coliformes termotolerantes, apenas os compostos resultantes do tratamento 1 estão de acordo com a referida Instrução Normativa (Tabela 9).

A baixa concentração de $\mathrm{NH}_{4}^{+}$(Tabela 9) confirma que os compostos atingiram a estabilidade. Os menores valores de $\mathrm{NO}_{2}{ }^{-}+\mathrm{NO}_{3}{ }^{-}$nos tratamentos com maior proporção de lodos de tanques sépticos refletem a baixa concentração de STV no substrato inicial. maior parte do nitrogênio total presente nos resíduos está na forma orgânica e, durante o processo de compostagem, esta passa da forma orgânica para a amoniacal e, em seguida, para 
SILVA, M. M. P.; SOUZA, J. T.; CEBALlOS, B. S. O.; FEITOSA, W. B. S.; LEITE, V. D. Tratamento aeróbio conjugado de lodos de tanques sépticos e resíduos sólidos orgânicos domiciliares. Ambi-Agua, Taubaté, v. 4, n. 3, p. 123-143, 2009. (doi:10.4136/ambi-agua.107)

nitrato. A ausência de nitrogênio na forma amoniacal indica que o composto está estabilizado (Kiehl, 1998).

Tabela 9. Características dos compostos obtidos dos diferentes tratamentos por cocompostagem de lodos de tanques sépticos com resíduos orgânicos domiciliares. Campina Grande-PB. Fevereiro de 2007.

\begin{tabular}{crrrcc}
\hline Parâmetros & T1 & T2 & T3 & T4 & Faixa ótima $^{(\mathbf{1})}$ \\
\hline $\mathrm{pH}$ & 9,2 & 8,4 & 8,6 & 8,7 & $>7$ \\
Umidade (\%) & 29,6 & 29,0 & 33,7 & 30,0 & $25-35$ \\
STV (\%ST) & 22,9 & 25,1 & 26,2 & 23,6 & $14<45$ \\
$\mathrm{COT}(\% \mathrm{ST})$ & 12,7 & 14,0 & 14,5 & 13,1 & $8<25$ \\
$\mathrm{NTK}(\% \mathrm{ST})$ & 1,2 & 1,3 & 1,15 & 1,1 & $>1$ \\
$\mathrm{C} / \mathrm{N}$ & 10,2 & 11 & 12,6 & 12,2 & $8-12$ \\
$\mathrm{NH}_{4}^{+}(\% \mathrm{ST})$ & 0,1 & 0,2 & 0,3 & 0,2 & 0,0 \\
$\mathrm{NO}_{2}^{-} \mathrm{NO}_{3}^{-}(\% \mathrm{ST})$ & 1,0 & 1,0 & 0,7 & 0,4 & $\mathrm{NE}$ \\
Helmintos (ovos viáveis/gST) & 0,0 & 0,0 & 0,0 & 0,0 & $<0,25$ \\
C. termotolerantes (NMP/gST) & $0,8 \times 10^{3}$ & $3,0 \times 10^{3}$ & $18,9 \times 10^{3}$ & $25,3 \times 10^{3}$ & $<10^{3}$ \\
\hline
\end{tabular}

NE: não especifica; ${ }^{1}$ Instrução Normativa n ${ }^{0}$ 23, de agosto de 2005 (Brasil, 2005); T1- 00\% de lodos; T2- 10\% de lodos; T3- 20\% de lodos; T4- 30\% de lodos.

De acordo com a Resolução 375/06 do CONAMA (Brasil, 2006a) e ponderando-se a ausência de ovos de helmintos (Tabela 9), todos os compostos podem ser enquadrados na classe A. Ao considerar a densidade de coliformes termotolerantes, apenas os compostos resultantes do tratamento $1\left(<10^{3} \mathrm{NMP} / \mathrm{gST}\right)$ podem ser assim classificados. Os compostos originados dos tratamentos 2, 3 e 4 enquadram-se na classe B $\left(<10^{6} \mathrm{NMP} / \mathrm{gST}\right)$.

A concentração de coliformes termotolerantes nos compostos aumentou em função da fração dos lodos de tanques sépticos, o que limita a seguridade sanitária para o uso de composto com alta fração de lodos de esgotos. Sabe-se, porém, que a dose mínima infectante calculada para bactérias patogênicas, encontra-se na ordem de $10^{2}$ a $10^{6}$ (USEPA, 1993) e que esses organismos são menos resistentes às condições ambientais adversas que os ovos de helmintos. Em culturas agrícolas, o tempo de sobrevivência de coliformes citado por Metcalf e Eddy (2003) é de 30-15 dias e em solo, 70-30 dias. De acordo com Medeiros et al. (1999), os maiores riscos de contaminação ocorrem durante e imediatamente após a aplicação dos lodos.

\subsection{Análise de Variância}

O teste de Levene indicou homogeneidade nas condições experimentais. Verificou-se normalidade dos possíveis erros experimentais. A partir do teste $\mathrm{F}$, observou-se efeito estatisticamente significativo ao nível de 5\% para as variáveis investigadas. $\quad \mathrm{Na}$ Tabela 10 apresentam-se os dados referentes ao coeficiente de variação (CV), Diferença Mínima Significativa (DMS) para os parâmetros: umidade, STV, relação C/N, NTK, Temperaturas da base, centro e superfície.

Os parâmetros relacionados diretamente com a transformação de matéria orgânica em mineral apresentaram os maiores coeficientes de variação (STV, C/N e NTK), em torno de $11 \%$. Considerando-se o período de co-compostagem, as semanas e a relação $\mathrm{C} / \mathrm{N}$ apresentaram o maior coeficiente de variação e a diferença mínima significante foi mais relevante entre as semanas.

A partir do teste de Tukey constatou-se que não ocorreu diferença estatística a $5 \%$ de probabilidade entre as médias dos tratamentos investigados, exceto para as temperaturas medidas no centro e na superfície (topo) do substrato para o tratamento 4 (T4). Neste tratamento, foram identificadas as menores temperaturas durante o monitoramento dos 
SILVA, M. M. P.; SOUZA, J. T.; CEBALlOS, B. S. O.; FEITOSA, W. B. S.; LEITE, V. D. Tratamento aeróbio conjugado de lodos de tanques sépticos e resíduos sólidos orgânicos domiciliares. Ambi-Agua, Taubaté, v. 4, n. 3, p. 123-143, 2009. (doi:10.4136/ambi-agua.107)

reatores, refletida na fase termófila mais curta, aumento do tempo para destruição ou inativação de ovos de helmintos (higienização), na menor velocidade de degradação do substrato $\left(\mathrm{K}_{\mathrm{STV}}=0,0069\right.$ dia $)$ e na menor eficiência de transformação do substrato em composto. Nas Tabelas 10 e 11, mostram-se as análises de variância pelo teste de Tukey, ao nível de $5 \%$ de probabilidade para os diferentes tratamentos e para as semanas, respectivamente.

Tabela 10. Análise de variância para os parâmetros: teor de umidade, STV, C/N e temperaturas para os diferentes tratamentos de co-compostagem de lodos de tanques sépticos com resíduos sólidos orgânicos domiciliares. Campina Grande-PB. Novembro de 2006 a fevereiro de 2007.

\begin{tabular}{l|rc|rc}
\hline \multirow{2}{*}{ Parâmetros } & \multicolumn{2}{|c|}{ Tratamento } & \multicolumn{2}{c}{ Semana } \\
\cline { 2 - 5 } & CV (\%) & DMS (5\%) & CV(\%) & DMS (5\%) \\
\hline Umidade (\%) & 5,2 & 1,6 & 5,7 & 3,6 \\
STV (\%ST) & 10,9 & 2,6 & 8,3 & 4,0 \\
C/N & 11,0 & 1,8 & 16,3 & 2,8 \\
NTK (\%ST) & 11,2 & 0,2 & 7,5 & 0,2 \\
Temperatura base $\left({ }^{\circ} \mathrm{C}\right)$ & 3,9 & 0,9 & 2,6 & 1,2 \\
Temperatura centro $\left({ }^{\circ} \mathrm{C}\right)$ & 4,6 & 1,1 & 2,5 & 1,2 \\
Temperatura superfície $\left({ }^{\circ} \mathrm{C}\right)$ & 4,4 & 1,0 & 3,4 & 1,6 \\
\hline
\end{tabular}

CV: coeficiente de variação; DMS: diferença mínima significativa.

Tabela 11. Análise de variância pelo teste de Tukey para os diferentes tratamentos de cocompostagem de lodos de tanques sépticos com resíduos sólidos orgânicos domiciliares. Campina Grande-PB. Novembro de 2006 a fevereiro de 2007.

\begin{tabular}{c|cccc|ccc}
\hline \multirow{2}{*}{ Tratamento } & \multirow{2}{*}{$\begin{array}{c}\text { Umidade } \\
\text { (\%) }\end{array}$} & $\begin{array}{c}\text { STV } \\
\text { (\%ST) }\end{array}$ & C/N & \multirow{2}{*}{$\begin{array}{c}\text { NTK } \\
\text { (\%ST) }\end{array}$} & \multicolumn{3}{|c}{ Temperatura $\left({ }^{\circ} \mathbf{C}\right)$} \\
\hline T1 & $44,73 a$ & $36,08 a$ & $13,05 a$ & $1,87 a$ & $33,70 a$ & $34,89 a$ & $34,48 a$ \\
T2 & $44,99 a$ & $34,38 a$ & $11,73 a$ & $1,99 a$ & $33,46 a$ & $34,20 a$ & $34,05 a$ \\
T3 & $45,79 a$ & $34,48 a$ & $12,31 a$ & $1,91 a$ & $33,46 a$ & $34,58 a$ & $34,25 a$ \\
T4 & $45,37 a$ & $32,94 a$ & $11,45 a$ & $1,96 a$ & $32,94 a$ & $33,16 b$ & $32,95 b$ \\
\hline
\end{tabular}

* Médias seguidas de mesmas letras não diferem estatisticamente entre si pelo teste de Tukey no nível de 5\% de probabilidade.

A ausência de diferença significativa entre os tratamentos pode ser explicada pelos princípios biológicos da compostagem. Frequentemente, de acordo com a constituição dos substratos, as diferenças são significativas nas primeiras semanas, uma vez que os organismos autóctones tendem a reduzir o estado de entropia, buscando condições favoráveis ao desempenho de suas funções. Na fase de maturação, as diferenças são mínimas e o composto resultante tende a reunir características físicas, químicas e sanitárias que atendam a uma faixa estabelecida pela legislação local vigente.

Os testes de Tukey realizados no nível de 5\% de probabilidade para os tratamentos e paras as semanas e aplicados aos dados coletados no período de 13 semanas referentes à estabilização: teor de umidade, percentual de STV e de NTK, relação C/N e temperatura, não permitiram identificar a fração de lodos de tanques sépticos mais adequada à co-compostagem com resíduos sólidos orgânicos domiciliares para o alcance dos objetivos para o tratamento desses resíduos: estabilização e higienização. No entanto, a diferença significativa registrada para os valores médios de temperatura em T4, a menor velocidade de degradação de STV em $\mathrm{T} 4\left(\mathrm{~K}_{\mathrm{STV}}=0,0069 \mathrm{dia}^{-1}\right)$ e de decaimento da relação $\mathrm{C} / \mathrm{N}\left(\mathrm{K}_{\mathrm{C} / \mathrm{N}}=0,0106 \mathrm{dia}^{-1}\right)$, alertam para as restrições de uso de fração de lodos superior a 20\%, principalmente, ao considerar que em T4 
SILVA, M. M. P.; SOUZA, J. T.; CEBALlOS, B. S. O.; FEITOSA, W. B. S.; LEITE, V. D. Tratamento aeróbio conjugado de lodos de tanques sépticos e resíduos sólidos orgânicos domiciliares. Ambi-Agua, Taubaté, v. 4, n. 3, p. 123-143, 2009. (doi:10.4136/ambi-agua.107)

foram registradas as menores temperaturas na superfície e no centro do substrato e que o tempo necessário à higienização foi maior. Além de que no composto resultante de T4 foi verificada a maior concentração de coliformes termotolerantes. Destaca-se que as menores médias de STV e $\mathrm{C} / \mathrm{N}$ foram constatadas em T4, embora não representem diferença significativa.

\section{CONSIDERAÇÕES FINAIS}

A transformação média de 54\% dos lodos dos tanques sépticos coletivos e dos resíduos orgânicos domiciliares (600 kg) em biossólidos classe A e classe B (324 kg) com características favoráveis à aplicação agrícola, somado à destruição total (100\%) dos ovos de helmintos no período de 91 dias, expressam o alcance dos objetivos do tratamento por cocompostagem dos lodos de tanques sépticos coletivos: estabilização e higienização.

A velocidade de biodegradação de $\operatorname{STV}\left(\mathrm{K}_{\mathrm{STV}}=0,0095 \mathrm{dia}^{-1}\right.$ a $\left.0,0069 \mathrm{dia}^{-1}\right)$ reduziu-se em função do aumento da fração de lodos de tanques sépticos coletivos, em 91 dias. No entanto, em todos os tratamentos, a constante de degradação ( $\left.\mathrm{K}_{\mathrm{STV}}\right)$ apresentou-se maior do que as obtidas nos trabalhos consultados $\left(\mathrm{K}_{\mathrm{stv}}=0,002992 \mathrm{dia}^{-1}\right.$ a $\left.0,004327 \mathrm{dia}^{-1}\right)$, no perído de 90 a 133 dias.

Nos substratos dos diferentes tratamentos, os ovos de Ascaris lumbricoides foram os mais resistentes, seguido de Fasciola hepatica, Trichuris trichiura e Taenea solium. Os ovos de Ancylostoma sp. e Enterobius vermiculares foram os de menor resistência. Do tratamento, resultaram biossólidos isentos desses organismos.

O uso de folhas, como estruturante na proporção de 10\% do total de resíduos sólidos orgânicos, favoreceu a redução do teor de umidade, propiciou espaços de aeração entre as partículas que constituíam os lodos de tanques sépticos coletivos e permitiram a superação do limite do uso de lodos de esgoto em relação à granulometria(fina).

O controle inicial do teor de umidade, da relação $\mathrm{C} / \mathrm{N}$, da granulometria e a definição da composição do substrato, revelaram-se fundamentais à ação dos organismos autóctones e para o alcance dos objetivos do tratamento dos lodos de tanques sépticos coletivos. O monitoramento, porém, deve ocorrer em todas as etapas da co-compostagem.

Em relação à fração de lodos de tanques sépticos coletivos, tomando-se por base o teste de Tukey, que evidenciou diferença estatística em nível de 5\% de probabilidade para as temperaturas na superfície e no centro do substrato do T4; considerando a menor velocidade de degradação de STV, o aumento do tempo necessário à destruição de ovos de helmintos, a elevação de coliformes termotolerantes no composto resultante desse tratamento, recomendase que a fração dos lodos de tanques sépticos coletivos em co-compostagem com resíduos orgânicos domiciliares não ultrapasse a 20\%. Frações superiores podem submeter os trabalhadores à maior probabilidade de contaminação durante a operação e o monitoramento dos sistemas e o odor exibido pelo composto pode limitar a aceitação por parte da população.

\section{REFERÊNCIAS}

ADHIKARI, B. K.; BARRINGTON, S.; MARTINEZ, J.; KING, S. Characterization of food waste and bulking agents for composting. Waste Management., v. 28, p. 795-804, 2008

AGUSTINI, D.; ONOFRE, S. B. Caracterização físico-química e microbiológica do lodo de esgoto produzido pela estação de tratamento de esgoto (ETE) de Pato Branco-PR. Revista de Biologia e Saúde da UNISEP Biology \& Health Journal., v. 1, n. 1 / 2, , p. 82-95, 2007. 
SILVA, M. M. P.; SOUZA, J. T.; CEBALlOS, B. S. O.; FEITOSA, W. B. S.; LEITE, V. D. Tratamento aeróbio conjugado de lodos de tanques sépticos e resíduos sólidos orgânicos domiciliares. Ambi-Agua, Taubaté, v. 4, n. 3, p. 123-143, 2009. (doi:10.4136/ambi-agua.107)

AMERICAN PUBLIC HEALTH ASSOCIATION (APHA), AMERICAN WATER WORKS ASSOCIATION (AWWA), WATER ENVIRONMENT FEDERATION (WEF). Standard Methods for the Examination of Water and Wastewater. 20. ed. Washington D.C: APHA, 1998. 936p.

ANDRADE NETO, C. O.; CAMPOS, J. R. Introdução. In: CAMPOS, J. R. (Coord). Tratamento de esgotos sanitários por processo anaeróbios e disposição controlada. Rio de Janeiro: ABES, 1999. 464 p. (PROSAB)

ANDREOLI, C. V.; VON SPERLING, M.; FERNANDES, F. Lodo de esgotos: tratamento e disposição final. Belo Horizonte: Departamento de Engenharia Sanitária e AmbientalUFMG, SANEPAR, 2001. 484p. (Princípios do Tratamento Biológico de Águas Residuárias, 6).

AQUINO, S. F.; CHERNICHARO, C. A. L. Acúmulo de ácidos graxos voláteis (AGVs) em reatores anaeróbios sob estresse; causas e estratégias de controle. Revista Engenharia Sanitária e Ambiental, v. 10, n. 2, p. 153-161, abr./jun. 2005.

BANEGAS, V.; MORENO, J. L.; GÁRCIA, C.; LEÓN, G.; HERMÁNDEZ, T. Composting anaerobic and aerobic sewage sludges using two proportions of sawdust. Waste Management., v. 27, n. 10, p. 1317-1327, 2007.

BARREIRA, L. P.; PHILIPPI JR., A.; RODRIGUES, M. S.. Usinas de compostagem do Estado de São Paulo: qualidade dos compostos e processos de produção. Revista de Engenharia Sanitária e Ambiental, v. 11, n. 4, , p.385-393, out;/dez. 2006.

BRASIL. Ministério do Meio ambiente. Conselho Nacional do Meio Ambiente. Resolução 375/2006 do CONAMA. Critérios e procedimentos para uso agrícola de lodo de esgoto gerado em estação de tratamento de esgoto sanitário. Brasília: CONAMA, 2006a.

BRASIL. Ministério do Meio ambiente. Conselho Nacional do Meio Ambiente Resolução 380/2006 do CONAMA. Retifica a Resolução 375/06. Brasília: CONAMA, 2006b.

BRASIL. Ministério da Agricultura, Pecuária e Abastecimento. Instrução Normativa $\mathbf{N}^{\circ} 23$ de 31 de agosto de 2005. Brasília: Diário Oficial da União, Seção 1, 8 de setembro de 2005.

CALLAGHAN, F. J.; WASE, D. A. J.; THAYANITHY, K.; FOSTER, C. F. Continuous codigestion of cattle slurry with fruit and vegetable wastes and chicken manure. Biomassa e Bioernergy., v. 27, p. 71-77, 2002.

CARRINGTON, E. G. Evaluation of sludge treatments for pathogen reduction. Final Report. Luxembourg: European Communities, Sep., 2001. 44 p.

CORREA, R. S.; FONSECA, Y. M. F.; CORREA, A. S. Produção de biossólidos agrícola por meio da compostagem e vermicompostagem de lodo de esgoto. Revista Brasileira de Engenharia Agrícola e Ambiental, Campiona Grande, v. 11, n. 4, p. 420-426, 2007.

CORREA, R. S.; WHITE, R. E.; WEATHERLEY, A. J. Biosolids on their ness to yield ryegrass based on their nitrogen content. Scientia Agricola, Piracicaba, v. 62, n. 3, p. 274-280, may/june, 2005.

FEACHEM, R. G.; BRADLEY, D. J.; GARELICK, H.; MARA, D. D. Sanitation and Disease: Health aspects of excreta and wastewater management. World Bank Studies in Water Supply and Sanitation 3, 501p. John Wiley and Sons, UK, 1983. 
SILVA, M. M. P.; SOUZA, J. T.; CEBALlOS, B. S. O.; FEITOSA, W. B. S.; LEITE, V. D. Tratamento aeróbio conjugado de lodos de tanques sépticos e resíduos sólidos orgânicos domiciliares. Ambi-Agua, Taubaté, v. 4, n. 3, p. 123-143, 2009. (doi:10.4136/ambi-agua.107)

GEA, T.; FERRER, P.; ÁlVARO, G.; VAlERO, F.; ARTOLA, A.; SÁNCHEZ, A. Cocomposting of sewage sludge: fats mixture and characteristies of the lípases involved. Biochemical Engineering Journal, v. 33, n. 3, p. 273-273, March 2007

HOORNWEG, D.; THOMAS, L.; OTTEN, L. Composting and its applicability in developing countries. Urban Waste Management. Working paper séries. Washington, D.C: The World Bank , 2000. 46 p.

KIEHL, E. J. Manual de compostagem: maturação e qualidade do composto. Piracicaba: USP, 1998. 171p.

KONÉ, D.; COFIE, O.; ZURBRUGG, C.; GALLIZZI, K.; MOSER, D.; DRESCHER, S.; STRAUSS, M. Helminth eggs inactivation efficiency by faecal sludge dewatering and co-composting in tropical climates. Water Research, v. 41, p. 4397- 4402, 2007.

KOOTTATEP, T.; POLPRASERT, C.; OANH, N. T. K.; MONTANGERO, A.; STRAUSS, M. Sludges from on site sanitation systems- low-cost treatment alternatives. In: IWA CONFERENCE ON WATER AND WASTEWATER MANAGEMENT FOR DEVELOPING COUNTRIES, 29-31 oct. 2001, Kuala Lampur. Anais... Kuala Lumpur: SANDEC, 2001. 10p. Disponível em: $<$ http://www.eawag.ch/organisation/abteilungen/sandec/publikationen>. Acesso: 10 jun. 2008.

KRANERT, M.; HAFNER, G.; BERKNER, I.; ERDIN, E. Compost from sewage sludge; a product with quality assurance system. Water Practice \& Technology: IWA Publishing. <http://www-32.cis.portlandcs.net/wpt/003/0008/0030008.pdf>, 2008.

LEITE, B. Z.; INGUNZA, M. P.; ANDEOLI, C. V. Lodo de decanto-digestores. In: ANDREOLI, C. V. (Org.). Alternativas de uso de resíduos de saneamento. Rio de Janeiro: ABES, 2006. 361p.

LIANG, C.; DAS, R. C.; McCLENDON, R. W. The influence of temperature and moisture contents regimes on the aerobic microbial activity of a biosolids composting blend. Bioresource Technology, v. 86, n. 2, p. 131-137, jan. 2003.

LU, L. A.; KUMAR, M.; TSAI, J. C.; LIN, J. G. High-rate composting of barley dregs with sewage sludge in a pilot scale bioreactor. Bioresource Technology, v. 99, n. 7, p. 2210-2217, may 2008.

MATOS, A. T.; VIDIGAL, S. M.; SEDIYAMA, M. A. N.; GARCIA, N. C. P.; RIBEIRO, M. F. Compostagem de alguns resíduos orgânicos, utilizando-se águas residuárias da suinocultura como fonte de nitrogênio. Revista Brasileira de Engenharia Agrícola e Ambiental, Campina Grande, v. 2, n. 2, p. 199-203, 1998.

MEDEIROS M. L.; THOMAZ SOCCOL V.; CASTRO, E. A.; TOLEDO, E. B.; BORGES, J. C.; PAULINO, R. C.; SILVA, S. M.; ANDRAUS, S. Aspectos Sanitários. In: Andreoli C, Fernandes F (eds) Reciclagem de Biossólido/ Transformando Problemas em soluções. Companhia de Saneamento do Paraná (SANEPAR), CDD 628.36, Curitiba, p. 120-179, 1999.

MEYER, K. B.; MILLER, K. D.; KANESHIRO, S. Recovery of Ascaris eggs from sludge. Journal of Parasitology, v. 64, n. 2. , p. 380-383, apr. 1978.

METCALF \& EDDY. Wastewater engineer treatment disposal, reuse. 4. ed. New York: McGRaw- Hill Book, 2003. 1729 p. 
SILVA, M. M. P.; SOUZA, J. T.; CEBALlOS, B. S. O.; FEITOSA, W. B. S.; LEITE, V. D. Tratamento aeróbio conjugado de lodos de tanques sépticos e resíduos sólidos orgânicos domiciliares. Ambi-Agua, Taubaté, v. 4, n. 3, p. 123-143, 2009. (doi:10.4136/ambi-agua.107)

MOHEE, R.; MUDHOO, A.; UNMAR, G. D. Windrow co-composting of shredded office paper and broiler litter. International Journal of Environment and Waste Management,. v. 2, n. 1/2, p. 3-23, 2008.

MONTANGERO, A.; BELEVI, H. Assessing nutrient flows in septic tanks by eliciting expert judgment: a promising method in the contexto of developing countries. Water Research, v. 41, n. 5, p. 1052-1064, 2007.

NEKLYUDOV, A. D.; FEDOTOV, G. N.; IVANKIN, A. N. Intensification of composting processes by aerobic microorganisms: a review. Applied Biochemistry and Microbiology, v. 44, n. 1, p. 6-18, 2008.

OGUNWANDE, G. A.; OGUNJIMI, L. A. O.; FAFIYEBI, J. O. Effects of turning frequency on composting of chicken litter in turned windrow piles. International Agrophypics, v. 22, p. 159-165, 2008a.

OGUNWANDE, G. A.; OSUNADE, J. A.; ADEKALU, K. O.; OGUNJIMI, L. A. O. Nitrogen loss in chicken litter compost as affected by carbon to nitrogen ratio and turning frequency. Bioresource Technology, v. 99, p. 7495-7503, nov. 2008b.

PINTO, M. T. Higienização do lodo. In ANDREOLI, C. V. (coord.). Resíduos sólidos do saneamento: processamento, reciclagem e disposição final. Rio de Janeiro: RIMA, ABES, 2001. 282p.

PRADHAN, S.; HOOVER, M. T.; CLARK, G. H.; GUMPERTZ, M.; WOLLUM, A. G.; COBB, C.; STROCK, J. Septic tank additive impacts on microbial populations. Journal of Environmental Health, v. 70, n. 6, p. 22-27, 2008.

SANTOS, J. W. dos; GHEYI, H. R. Estatística experimental aplicada. Campina Grande: Marcone,. 213p. Tópicos de Engenharia Agrícola e Agronômica. 2003.

SILVA, M.; M.; P.. Tratamento de lodos de tanques sépticos por co-compostagem para os municípios do semi-árido paraibano: alternativa para mitigação de impactos ambientais. 2008. 219f. Tese (Doutorado do Programa de Pós-Graduação em Recursos Naturais), Universidade Federal de Campina Grande, Campina Grande, 2008.

SILVA, A. G; LEITE, V. D.; SILVA, M. M. P.; PRASAD, S.; FEITOSA, W. B. S. Compostagem aeróbia de lodo de tanque séptico e resíduos sólidos vegetais. Revista de Engenharia Sanitária e Ambiental, v. 13, n. 4, p. 371-379, out./dez. 2008.

SINGH, R. P.; AGRAWAL, M. Potencial benefits and application of sewage sludge. Waste Management, v. 28, n. 2, p. 347-358, 2008.

SUMMERFELT, R. C.; PENNE, C. R. Septic tank treatment of the effluent from a smallscale comercial recycle aquaculture system. North American Journal of Aquaculture, v. 69, p. 59-68, 2007.

TAVARES, J. C. C.; PINHEIRO, Q. M. L.; CALLADO, N. H. Levantamento da composição gravimétrica dos resíduos sólidos urbanos da cidade de Maceió. In: CONGRESSO BRASILEIRO DE ENGENHARIA SANITÁRIA E AMBIENTAL, 24, 2007, Belo Horizonte. Anais... Belo Horizonte: ABES, 2007.

TOGNETTI, C.; MAZZARINO, M. J.; LAOS, F. Co-composting biosolids and municipal organic waste: effects of process management on stabilization and quality. Journal Biology and Fertility of Soils, v. 43, n. 4, p. 387-39, march 2007. 
SILVA, M. M. P.; SOUZA, J. T.; CEBALlOS, B. S. O.; FEITOSA, W. B. S.; LEITE, V. D. Tratamento aeróbio conjugado de lodos de tanques sépticos e resíduos sólidos orgânicos domiciliares. Ambi-Agua, Taubaté, v. 4, n. 3, p. 123-143, 2009. (doi:10.4136/ambi-agua.107)

UNITED STATE ENVIRONMENTAL PROTECTION AGENCY - USEPA. EPA/625/R92/013. Environmental regulations and technology; control of pathogens and vector attraction in sewage sludge. Washington: Environmental Protection Agency, 2003. 119p.

UNITED STATE ENVIRONMENTAL PROTECTION AGENCY - USEPA EPA 832-F-99075. Tanque séptico - sistemas de absorción al suelo. Folleto Informativo de sistemas descentralizados. Washington: Environmental Protection Agency, 1999a.

UNITED STATE ENVIRONMENTAL PROTECTION AGENCY - USEPA. Part 530.R-99009. Office of solids waste biosolids generation, use and disposal in the United States. Washington: Environmental Protection Agency, 1999b.

UNITED STATE ENVIRONMENTAL PROTECTION AGENCY - USEPA. 40 CFR-Part 503. Use or disposal of sewage sludge; biosolids. Washington: Environmental Protection Agency, 1993.

VAN HAANDEL, A. C.; ALÉM SOBRINHO, P. Produção, composição e constituição de lodo de esgoto. In: ANDREOLI, C. V. (Coord.). Alternativas de uso de resíduos do saneamento: biossólidos. Rio de Janeiro: ABES, 2006. 417p. (Projeto PROSAB) 